\title{
THE SKULL AND PECTORAL GIRDLE OF THE PARASEMIONOTID FISH WATSONULUS EUGNATHOIDES FROM THE EARLY TRIASSIC SAKAMENA GROUP OF MADAGASCAR, WITH COMMENTS ON THE RELATIONSHIPS OF THE HOLOSTEAN FISHES
}

\author{
PAUL ERIC OLSEN \\ Lamont-Doherty Geological Observatory, Department of Geology, Columbia University, Palisades, New York 10964
}

\begin{abstract}
Watsonulus eugnathoides (Piveteau, 1935) is a parasemionotid fish from Early Triassic rocks of Madagascar. The skull and pectoral girdle of this holostean are described from new material. The braincase retains a number of primitive chondrostean-like characters such as an open lateral cranial fissure and frequently open vestibular fontanelle, presence of an endochondral intercalar without membranous outgrowths, and fusion between most of the the endochondral bones in the adult, but is otherwise similar to "caturids" such as Heterolepidotus. The dermal skull retains one major, putatively primitive, feature shared with chondrosteans, a preopercular with a broad dorsal edge. The dermal shoulder girdle retains a chondrostean-style clavicle, but the endochondral shoulder girdle is most similar to teleosts among actinopterygians. Watsonulus also has an Amia-style jaw joint. The nonreduced clavicle and dorsally expanded preoperculum are lost in all other non-parasemionotid neopterygians (the reductions being synapomorphies), and the combination of these two primitive characters with an Amia-style jaw in Watsonulus shows that gars and teleosts are more closely related to each other than either is to Amia.
\end{abstract}

\section{DEDICATION AND INTRODUCTION}

Fourteen years ago I was introduced to Bobb Schaeffer in the old preparation room in the American Museum of Natural History. I was 15 years old and had with me my first fossil fish, a fragment of a semionotid from the Early Jurassic of New Jersey. Bobb spent a long time with me that day working out an identification. In the subsequent two years he made available to me the Osborn Library and fossil fish collection at the American Museum, and spent scores of hours with me during my frequent, totally unannounced visits. His continuous tutelage and encouragement in my early years opened up for me the door to professional scientific inquiry. Thus, it is to Bobb Schaeffer that I dedicate this paper, the first in a planned series of papers on the origin, relationships, and significance of the holostean fishes.

Here I describe the skull and shoulder girdle of the fish Watsonulus euganthoides (Piveteau, 1935), and attempt to place that taxon within a phylogenetic framework of holosteans and teleosts suggested by the combination of characters seen in Watsonulus. Watsonulus has always been considered a representative of a group of Triassic fishes called parasemionotids, which have been variously hypothesized to be a basal grade within the holosteans or ancestral to Amia-like fishes and/or teleosts (Brough, 1939; Gardiner, 1960; Patterson, 1973; Nybelin, 1966). The new material of Watsonulus and the material described in the literature reveal character combinations completely incompatible with all previously proposed schemes of relationships for the neopterygians and suggest a new hypothesis in which Amia is regarded as the primitive sister group of all living neopterygians.

\section{MATERIAL AND METHODS}

All the specimens described in this paper were collected during 1961 by Professor Bernard Kummel of the Harvard Museum of Comparative Zoology from the famous nodule-bearing beds in the Early Triassic of Madagascar (Piveteau, 1935; Lehman, 1952) at Ambilombe Bay. These units belong to "Bed 5" of the Middle Sakamena Group of probable Scythian age (Anderson and Anderson, 1973).

The utility of this new material of Watsonulus rests in the virtually uncrushed nature of the bones, the partial disarticulation of the skulls, and the preservation of fine surface detail. However, these specimens are preserved as hard siltstone nodules in which virtually all the bone has been leached out. During collection, each nodule was split into two halves exposing a hole which is the natural mold of the bones. Therefore, for their exceptional utility to be fully realized, the nodules must be cast in a flexible molding compound such as latex, Smooth-On, or silicone as described by Baird $(1951,1974)$ and used with great success by Schaeffer $(1967,1978)$. After much 


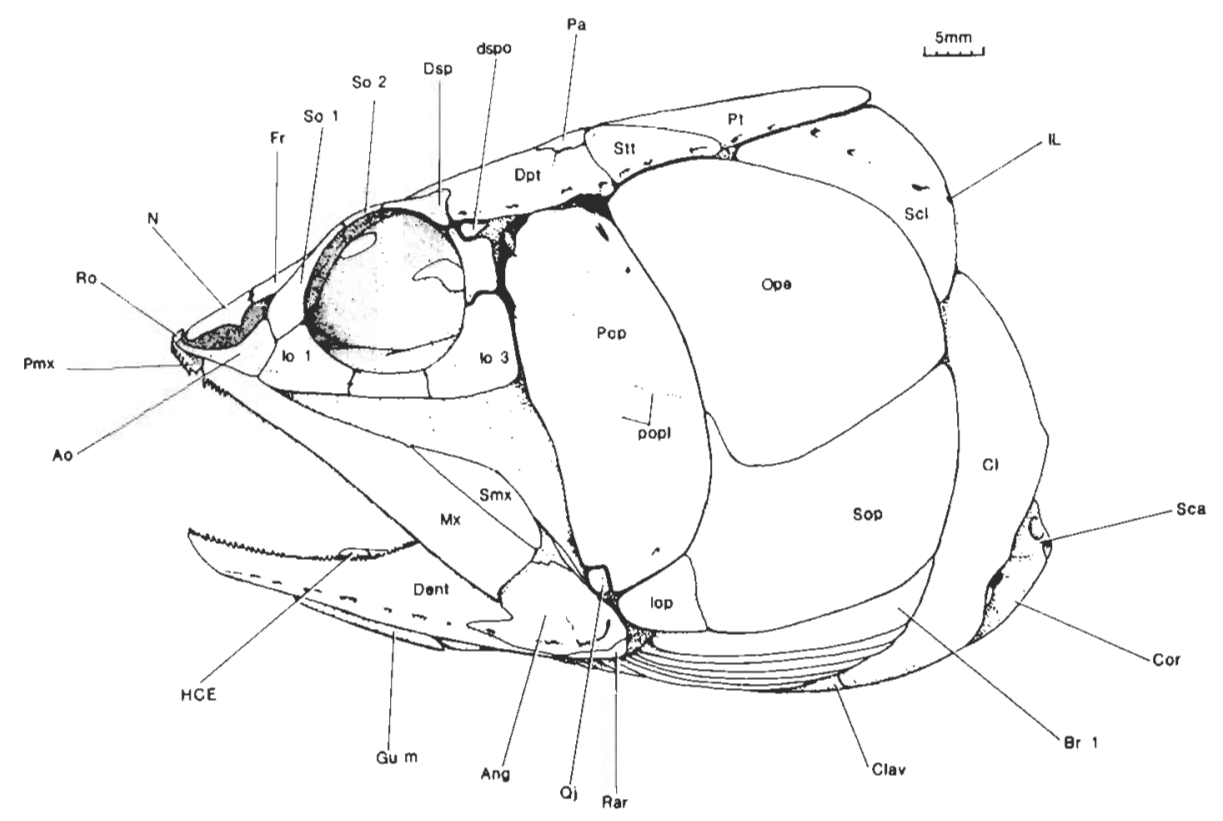

FIGURE 1. Reconstruction of Watsonulus eugnathoides in lateral view. Abbreviations: Ang, angular; Ao, antorbital; Br 1, first branchiostegal; Cl, cleithrum; Clav, clavicle; Cor, coracoid portion of endoskeletal shoulder girdle; Dpt, dermopterotic; Dsp, dermosphenotic; dspo, exposed portion of sphenotic; Fr, frontal; Gu m, medial gular; HCE, hypohyal and ceratohyal; IL, lateral line; Io 1, Io 3, infraorbitals one and three; Iop, interopercular; $\mathbf{M x}$, maxillary; $\mathbf{N}$, nasal; Ope, opercular; Pa, parietal; Pmx, premaxillary; Pop, preopercular; popl, preopercular pit line; Pt, post-temporal; Qj, quadratojugal; Rar, retroarticular; Ro, rostral; Sca, scapular region of endoskeletal shoulder girdle; Scl, supercleithrum; Smx, supramaxillary; So 1, So 2, supraorbitals one and two; Sop, subopercular; Stt, supratemporal.

experimentation, Smooth-On brand (type FMC 100) polysulfide molding compound has proved to be the best molding material for making the casts from the natural molds, because it pulls out easily from deep recesses without ripping or damaging the fossil.

First, the nodules were thoroughly cleaned. Occasionally films of iron oxides coat the mold surface and these can be removed by lengthy soaking in $\mathrm{HCl}$. This tends, however, to soften the nodules. When $\mathrm{HCl}$ was used, the nodules were rinsed in water, deacidified with dilute ammonium hydroxide, washed in water for several days to remove the resulting salts, and dried. This is necessary because $\mathrm{HCl}$ reacts with Smooth-On. A release agent of Ivory Liquid-brand soap mixed with ethanol was very liberally applied and allowed to soak in and dry. Smooth-On was forced into all recesses with a small ( $3 \mathrm{~mm}$ wide) bristle brush and then poured in to completely cover the nodule. After curing, the cast was pulled (carefully) from the mold. These flexible casts can be cut so that three-dimensional elements can be examined unobstructed from several directions. In most cases, the resulting Smooth-On casts were studied directly under a Wild binocular microscope with a drawing tube attachment (camera lucida) and detailed $6 \times$ drawings were prepared.

In the cases where the braincase was preserved in both halves of the nodules, it was possible to make Dow-Corning Silicone (type 3110 RTV) molds of the
Smooth-On casts. [Type 3110 RTV silicone does not react with the Smooth-On, but most other molding compounds do and will dissolve or will not cure.] These Silicone molds are, of course, flexible duplicates of the original nodules. Dental plaster was poured into both halves of the Silicone molds, and the halves were fitted together before the plaster cured. The results are completely three-dimensional casts of braincases which can be examined from all angles as if they were actual bone, freed from matrix. It is from these casts (in addition to the Smooth-On casts made directly from the nodules) that the reconstructions of the braincase in Figures $6-8$ and 11 were prepared.

In order to prepare an accurate reconstruction drawing of the articulated Watsonulus skull, a $6 \times$ enlarged wax and cardboard model was prepared from tracings of the camera lucida drawings of the actual specimens. The final reconstruction drawings (Figs. 1-3) were made from photographs of the model.

Cited Specimens-Specimens in Vertebrate Paleontology collections of the Museum of Comparative Zoology (Harvard University, Cambridge, Massachusetts), numbers MCZ 13871-13878, corresponding to casts of those specimens in the Vertebrate Paleontology collections of the Peabody Museum of Natural History (Yale University, New Haven, Connecticut), numbers YPM 8934, 8935, 8989, 8990, 8991, 8992, 8994, 8995, 8996. 


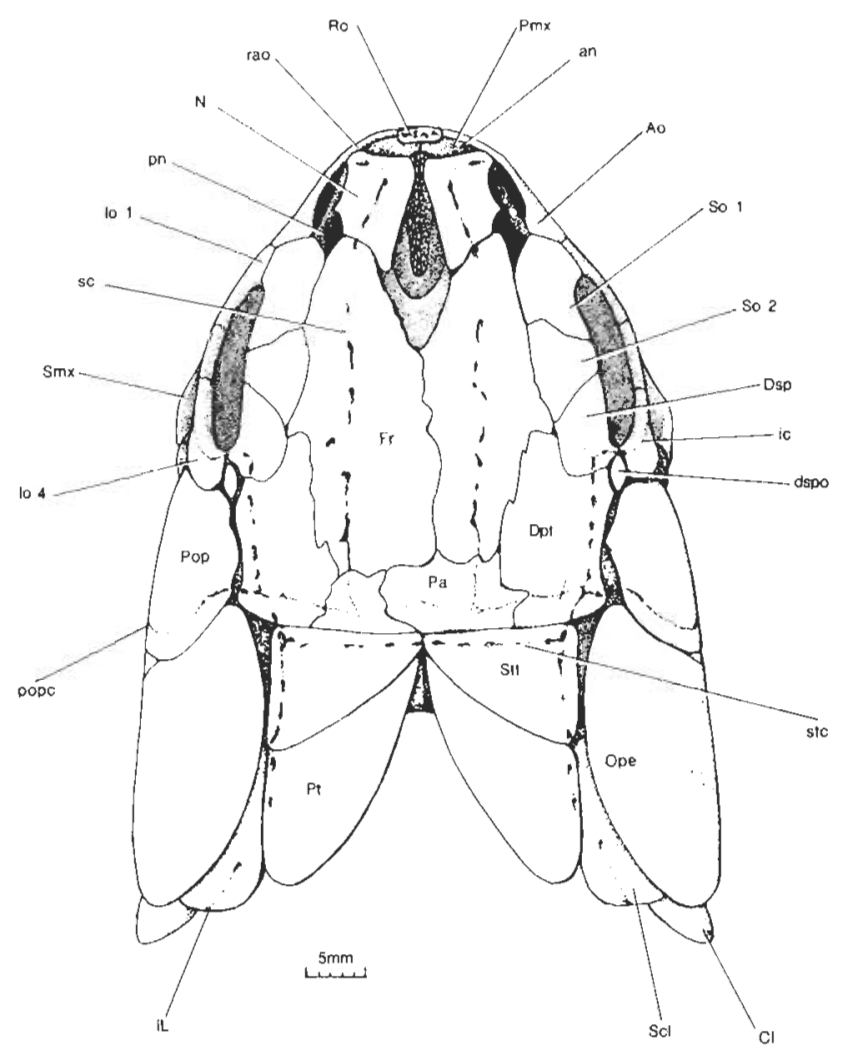

FIGURE 2. Reconstruction of Watsonulus eugnathoides in dorsal view. Abbreviations: an, anterior nasal opening; Ao, antorbital; Cl, cleithrum; Dpt, dermopterotic; Dsp, dermosphenotic; dspo, exposed portion of sphenotic; $\mathbf{F r}$, frontal; ic, infraorbital canal; IL, lateral line; Io 1, Io 4, infraorbitals one and four; N, nasal; Ope, opercular; Pa, parietal; Pmx, premaxillary; pn, posterior nasal opening; Pop, preopercular; popc, preopercular canal; Pt, post-temporal; rao, rostral portion of antorbital; Ro, rostral; sc, supraorbital canal; Smx, supramaxillary; So 1, So 2, supraorbitals one and two; stc, supratemporal canal; Stt, supratemporal.

\section{TAXONOMY}

Piveteau (1935) named and described a series of specimens from the Middle Sakamena Group, preserved as natural molds in nodules, as Watsonia eugnathoides. Brough (1939) amended the name to Watsonulus, because Watsonia was preoccupied at least three times. Under Watsonia eugnathoides (now Watsonulus), Piveteau described three variants which he termed types A, B, and C. The material described here is indistinguishable from Piveteau's type A specimens and the material described by Beltan (1968) as Watsonulus eugnathoides. There are differences in degrees of ossification among the individual specimens, but the total range in size of all the neurocrania I have examined is $41.0-45.2(\mathrm{~N}=5$, mean $=43.0 \pm 1.1$ $\mathrm{mm}$ ), which is what might be expected of a single fish

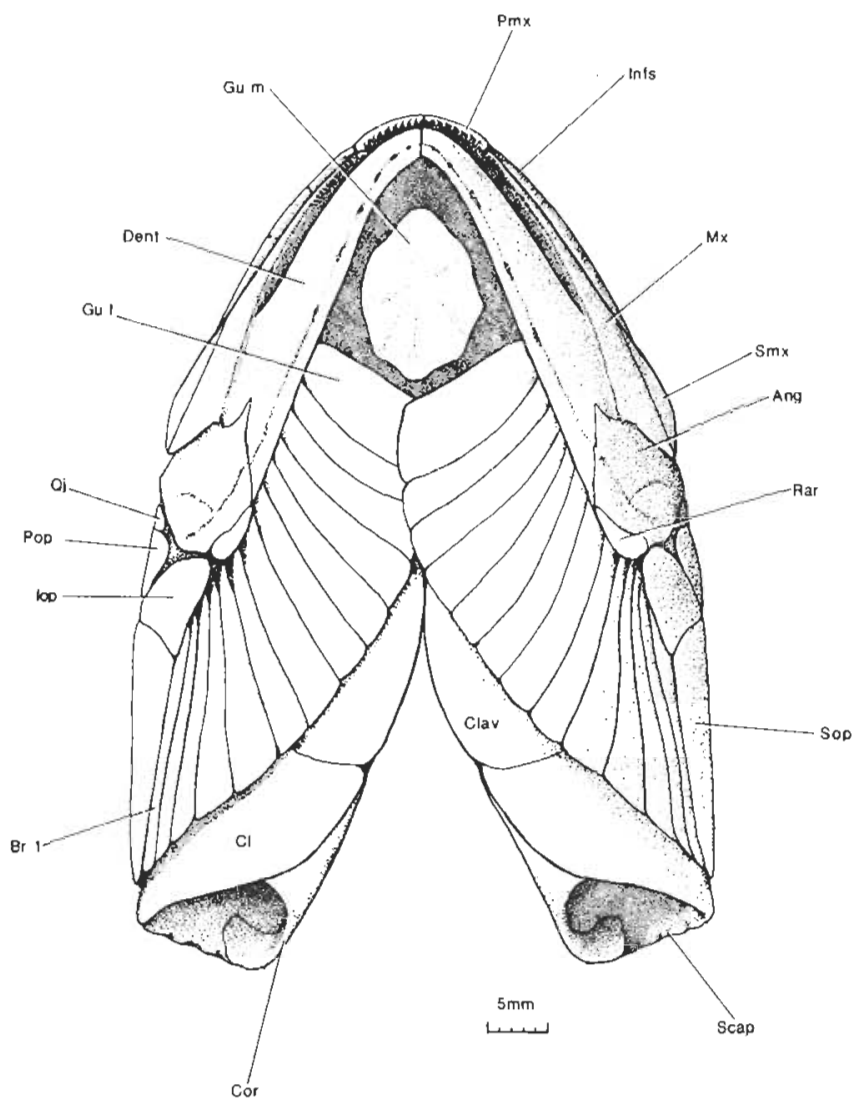

FIGURE 3. Reconstruction of Watsonulus eugnathoides in ventral view, based principally on YPM 8995. Abbreviations: Ang, angular; Br 1, branchiostegal one; Cl, cleithrum; Clav, clavicle; Cor, coracoid portion of endoskeletal shoulder girdle; Dent, dentary; Gu 1, lateral gular; Gu m, medial gular; Infs, infraorbitals; Iop, interopercular; Mx, maxillary; Pmx, premaxillary; Qj, quadratojugal; Rar, retroarticular; Scap, scapular region of endoskeletal shoulder girdle; Smx, supramaxillary; Sop, subopercular.

species that shows determinate growth. There is very little variability in skull-bone shape or dermal sculpture, and I therefore feel confident that the range of variation seen in the specimens here described under the name $W$. eugnathoides can be comfortably enclosed in a single species. There are definite similarities, however, to other parasemionotid genera described from Madagascar, especially Beltan's (1968) Devillersia and Piveteaunotus, and to the Early Triassic forms from East Greenland, Broughia and Ospia (Stensiö, 1932), and it is possible that the material described here more properly belongs in one of these genera or vice-versa. These other genera are known from much less complete and less well preserved material than Watsonulus, however, and it is clear that first-hand examination of the type material will be necessary for the material described here to be unambiguously as- 


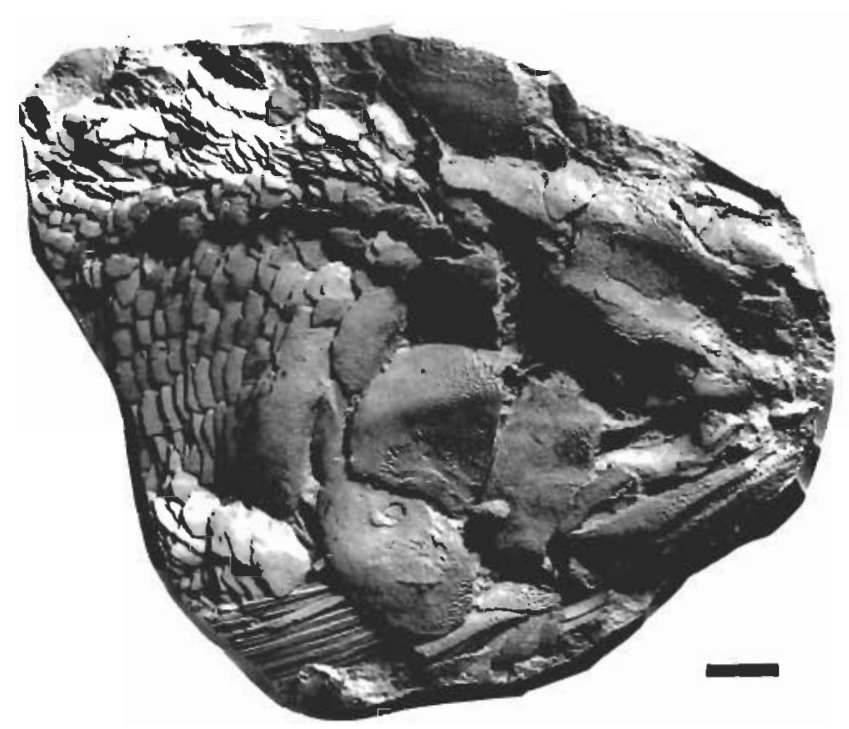

FIGURE 4. Watsonulus eugnathoides, Smooth-On cast of nodule, YPM 8894. Scale bar equals $5 \mathrm{~mm}$.

signed to Watsonulus or some other form. Such a taxonomic study is beyond the scope of this work, and because the goals of the paper are the elucidation of morphology and phylogenetic relationships of the specimens described here to taxa outside the "Parasemionotidae," such a taxonomic treatment is, for the moment, unnecessary.

\section{DESCRIPTION}

\section{Neurocranium}

In the degree of ossification, proportions, and many other details, the neurocranium of Watsonulus is similar to Heterolepidotus (Patterson, 1975), Macrepistius (Schaeffer, 1971), Caturus (Rayner, 1948), and, of course, other parasemionotids, especially the Early Triassic specimen from East Greenland figured by Patterson (1975, figs. 24-28). As in Heterolepidotus and most described parasemionotids, the sutures between most bones are not visible, and hence the extent of bones such as the opisthotic, epioccipitals, and pterotics cannot be ascertained. In lateral view, Watsonulus can be seen to differ from Heterolepidotus principally in the presence of an open vestibular fontanelle, persistence of the lateral cranial fissure, and lack of membranous outgrowth of the intercalar (Figs. 6, 8)all almost certainly primitive features.

In specimens of Watsonulus the closure of the vestibular fontanelle is variable. Usually, however, at least part remains open (Figs. 6, 8, 9) (Beltan, 1968), the opening being surrounded by very thin bone. Posteriorly the fontanelle opens into the ventral portion of the lateral cranial fissure which extends dorsally at least to the intercalar. The extent of both the lateral cranial

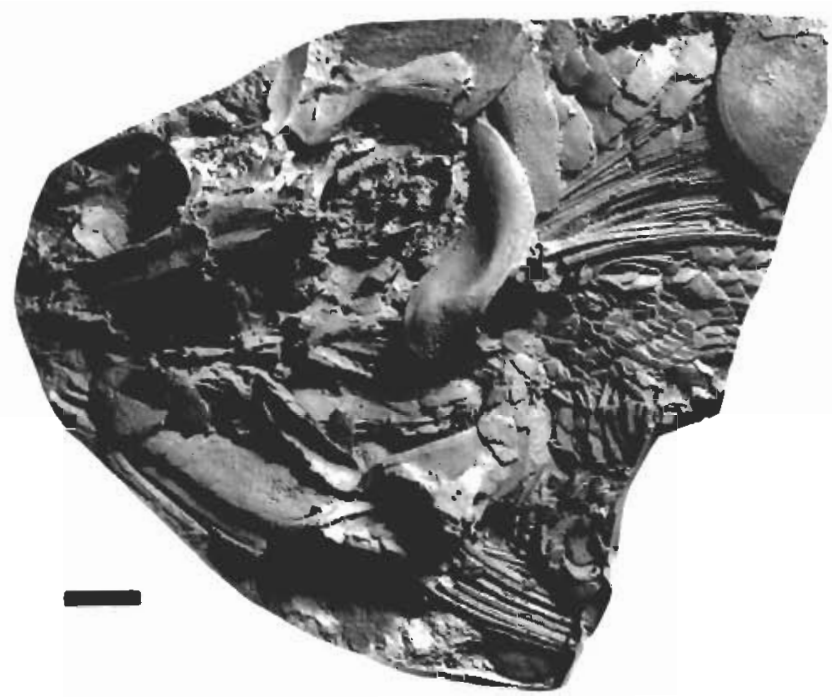

FIGURE 5. Watsonulus eugnathoides, Smooth-On cast, counterpart to YPM 8894.

fissure and the vestibular fontanelle is therefore similar to that of Parasemionotus (Lehman, 1952) and Broughia (Stensiö, 1932).

The intercalar is a half-spool-shaped bone possibly partially enclosing the foramen for nerve $\mathrm{X}$; it lacks the membranous outgrowths seen in Heterolepidotus, Macrepistius, Caturus, and Amia, and more or less conforms to Patterson's (1975) description of the intercalar in his undetermined parasemionotid, although it is larger and fused with adjoining bones.

In lateral view, the ethmoidal region is again closely similar to what is seen in Heterolepidotus, and both of these are closely comparable to $A$ mia (Fig. 6). The main difference between Watsonulus and Amia is in the greatly reduced ossification in the latter and the much less extensive premaxillae in Watsonulus.

In ventral view (Figs. 6, 8, 10) the parasphenoid floors the ventral side of the neurocranium and extends from nearly the anterior tip of the ethmoidal ossifications to two-thirds of the way along the basioccipital. It does not, therefore, extend as far posteriorly as in Amia or Heterolepidotus. The basipterygoid processes are prominent, with a possible prootic component. There is a notch behind the ascending wing of the parasphenoid for the internal carotid artery, and a notch in front of the basipterygoid processes for the efferent pseudobranchial artery as in Amia, Heterolepidotus, and other parasemionotids. The ascending portion of the lateral wing of the parasphenoid is divided into two lamellae: a longer one, which covers the prootic and sphenotic groove for the spiracular canal; and a shorter and more posterior one, which extends towards the posterior opening of the jugal canal. A large, raised patch of very numerous tiny teeth covers most of the 


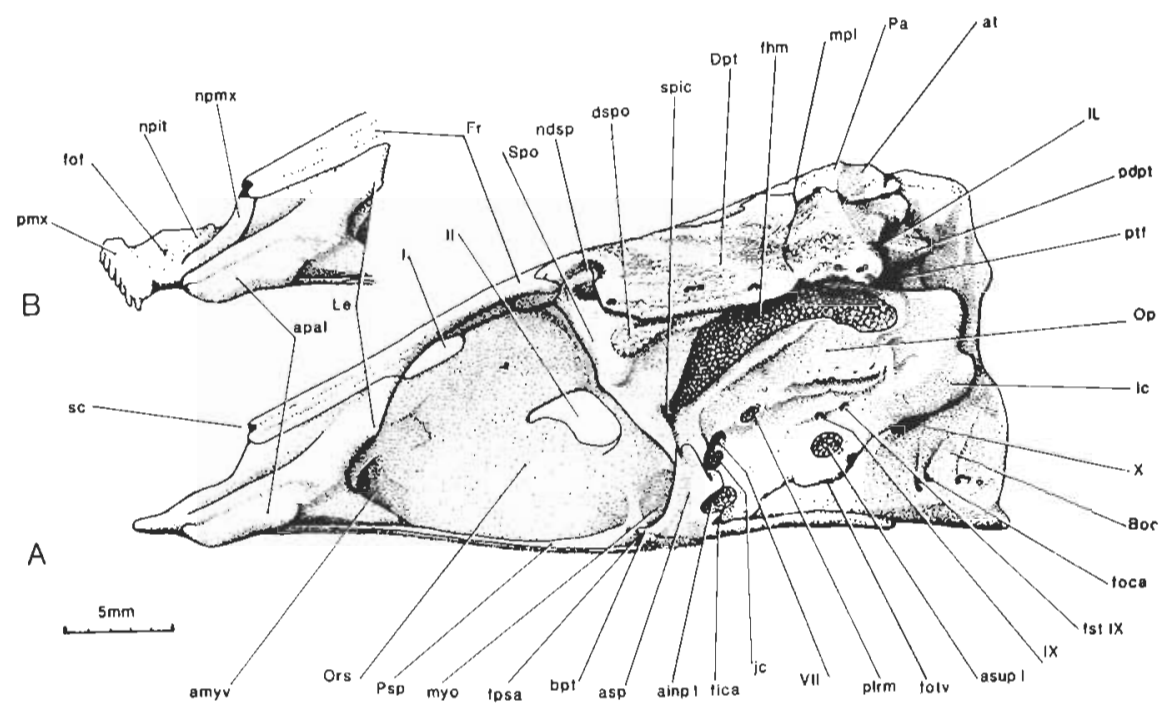

FIGURE 6. Lateral view of braincase of Watsonulus eugnathoides without premaxilla (A) and with premaxilla (B), based principally on YPM 8989, 8890, 8894, and 8835. Abbreviations: I, foramen for olfactory tracts; II, optic fenestra; VII, foramen for facial nerve; IX, foramen for glossopharyngeal nerve; $\mathbf{X}$, foramen for vagus nerve; anip $\mathbf{I}$, articular facet for first infrapharyngobranchial; amyv, anterior myodome; apal, articular facet for palatoquadrate complex; asp, ascending wing of parasphenoid; asup I, articular facet for first? suprapharyngobranchial; at, area of overlap of supratemporal on parietal and dermosphenotic; Boc, basioccipital; bpt, basipterygoid process; Dpt, dermopterotic; dspo, exposed portion of sphenotic (note dermal sculpture); fhm, hyomandibular facet; fica, foramen for internal carotid artery; foca, foramen for occipital artery; fof, foramen for olfactory branch of palatine nerve; fotv, fissura oticalis ventralis and area of vestibular fontanelle (when open); fpsa, foramen for efferent pseudobranchial artery; Fr, frontal; fst IX, foramen for supratemporal branch of glossopharyngeal nerve; Ic, intercalar; IL, lateral line; jc, jugal canal; Le, lateral ethmoid; mpl, middle pit line; myo, posterior myodome; ndsp, notch for dermosphenotic; npit, nasal pit; npmx, nasal process of premaxillary; Op, opisthotic; Ors, orbitosphenoid bone; Pa, parietal; pdpt, posterior process on dermosphenotic; plrm, process on prootic for origin of branchial levator muscles; pmx, premaxillary; Psp, parasphenoid; ptf, post-temporal fossa; sc, supraorbital canal; spic, spiracular canal; Spo, sphenotic.

parasphenoid from the level of the notches for the internal carotid arteries to the level of articular surfaces for the palatoquadrate on the ethmoidal region (Figs. $8,10)$.

During the preparation of YPM 8990 it was possible to determine the extent of the notochordal canal before the natural mold of the basioccipital was opened (Figs. $9,10)$. The postero-ventral wall of the cranial cavity was thus revealed free of the parasphenoid and basioccipital. The extent of this wall anteriorly indicates the position of the ventral cranial fissure which evidently was cartilage-filled in this form. The cone-shaped canal for the anterior part of the notochord extends forward, presumably ending on the cartilage wall filling the fissure. The canal for the notochord clearly places a limit on the backward extent of the posterior myodome, which apparently ended just behind the ascending wings of the parasphenoid.

The sphenotic (Figs. 6, 11) is a large, cone-shaped bone very similar in position and shape to that bone in Heterolepidotus and Patterson's (1975) undetermined parasemionotid. Bartram (1975) found that in Ophiopsis and Macrepistius, and possibly in Furo and
Heterolepidotus, the sphenotic is partially exposed between the dermosphenotic, dermopterotic, and first circumorbital. This is definitely the case in Watsonulus as well. The exposed portion of the sphenotic is covered by dermal ornamentation characteristic of the rest of the skull roof (Figs. 1, 6, 7). The distribution of this character among actinopterygians is very poorly known, and was thought by Bartram to be characteristic only of Ophiopsis-like caturids. However, although this character has never been described in gars, both Atractosteus and Lepisosteus have a small portion of the sphenotic exposed in the skull roof, and this feature may be present in Lepidotes and Newark Supergroup semionotids as well (Olsen and McCune, in prep.). Like the surrounding dermal bones of the skull, the possible sphenotic in these latter forms is not ornamented.

In ventral view (Figs. 8,9 ), it can be seen that the spiracular canal enters the sphenotic from the parasphenoid without passing through a roofed canal in the prootic, as in Amia and Heterolepidotus (Patterson, 1975). The spiracular canal passes through the sphenotic, opening on its dorsal surface beneath the dermopterotic (Fig. 7). 


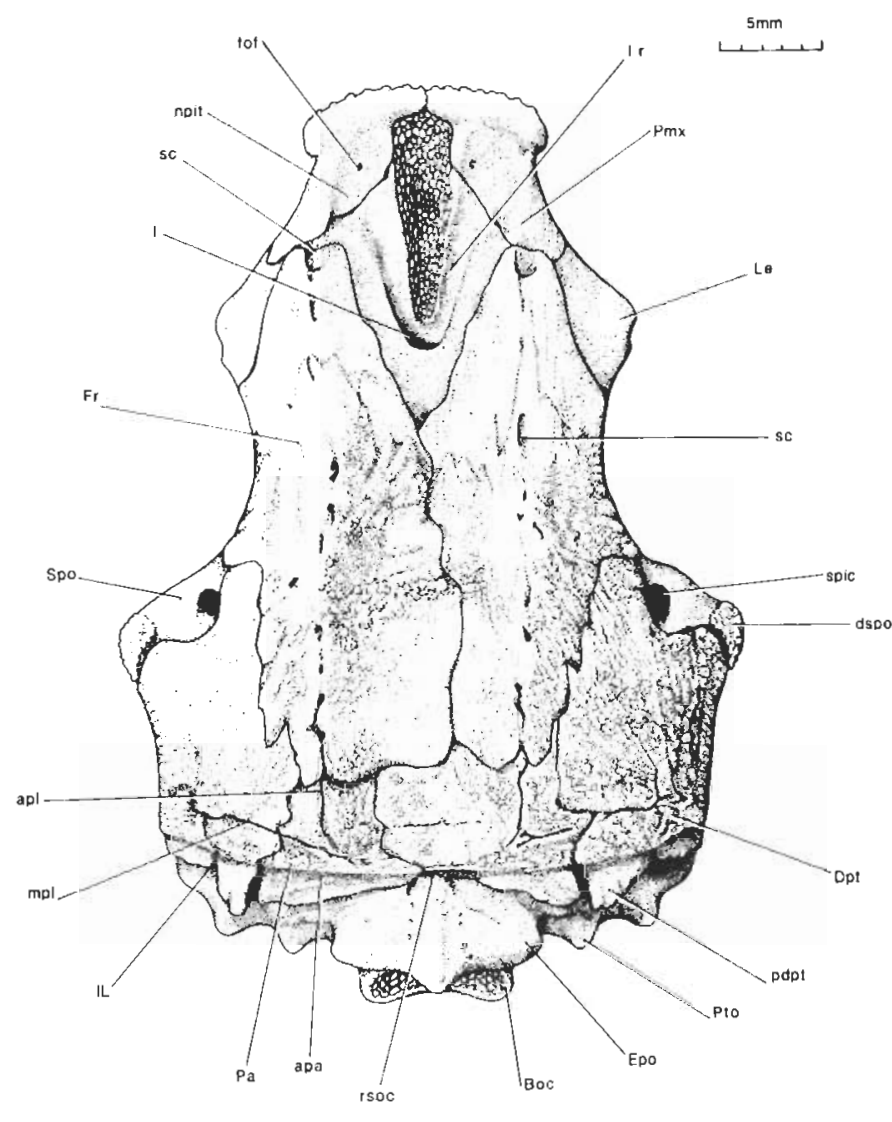

FIGURE 7. Dorsal view of braincase of Watsonulus eugnathoides based principally on YPM 8834 and 8835. Abbreviations: I, foramen for olfactory tracts; Ir, groove for right branch of olfactory tracts; apa, area of overlap of supratemporal on parietal; apl, anterior pit line; Boc, basioccipital; Dpt, dermopterotic; dspo, exposed portion of sphenotic (note dermal sculpture); Epo, region of epiotic; fof, foramen for olfactory branch of palatine nerve; Fr, frontal; IL, lateral line; Le, lateral ethmoid; mpl, middle pit line; ndsp, notch for dermosphenotic; npit, nasal pit; Pa, parietal; pdpt, posterior process on dermosphenotic; pmx, premaxillary; Pto, pterotic; rsoc, recess on roof of otic region; sc, supraorbital canal; spic, spiracular canal; Spo, sphenotic.

The dermosphenotic (Figs. 1, 2, 4) resembles a circumorbital in that it consists of a simple plate and does not seem to wrap around the anterior face of the sphenotic, although it does cap it. It is also displaced in all the specimens I have looked at. On the other hand, it fits into the notch in the dermopterotic, and the dorsal and orbital surface of the dermosphenotic are continuous with the dorsal and orbital surfaces of the dermopterotic and sphenotic, respectively. The posteroventral portion of the dermosphenotic carrying the infraorbital canal is elongated, passing anterior to the exposed portion of the sphenotic.

The structure of the orbital wall of the braincase (Fig. 11 ) is somewhat difficult to interpret because it is im-

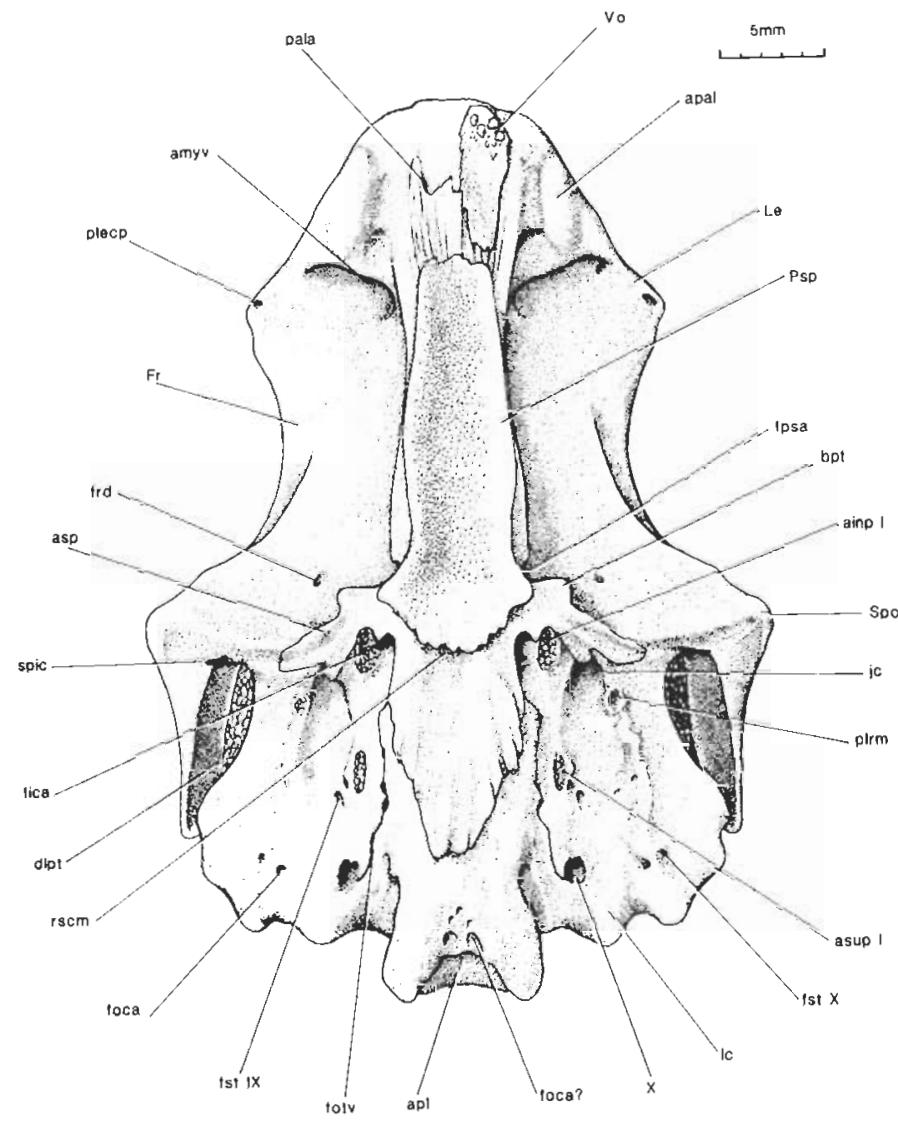

FIGURE 8. Ventral view of the braincase of Watsonulus eugnathoides. Right side drawn without vomer. Based principally on YPM 8990, 8994, and 8995. Abbreviations: X, foramen for vagus nerve; anip I, articular facet for first infrapharyngobranchial; amyv, anterior myodome; apal, articular facet for palatoquadrate complex; asp, ascending wing of parasphenoid; asup I, articular facet for first? suprapharyngobranchial; bpt, basipterygoid process; dlpt, descending lamina of dermopterotic; fica, foramen for internal carotid artery; foca, foramen for occipital artery; fotv, fissura oticalis ventralis and area of vestibular fontanelle (when open); fpsa, foramen for efferent pseudobranchial artery; Fr, frontal; frd, foramen for ascending branch of superficial ophthalmic nerves; fst IX, foramen for supratemporal branch of glossopharyngeal nerve; fst $\mathbf{X}$, foramen for supratemporal branch of vagus nerve; Ic, intercalar; jc, jugal canal; Le, lateral ethmoid; plecp, pit housing origin of ligament to ectopterygoid; pala, canal for anterior branch of palatine nerve; plrm, process on prootic for origin of branchial levator muscles; Psp, parasphenoid; rscm, recess on parasphenoid containing area of origin of subcephalic muscles; spic, spiracular canal; Spo, sphenotic; Vo, vomer.

possible to follow the course of canals into bones; however, resemblance to that region in Heterolepidotus (Patterson, 1975, fig. 93) is obvious and closer than to any other described fish. As in Heterolepidotus, the trigeminofacialis chamber is pholidophorid-like, with a single posterior opening and a very short lateral com- 


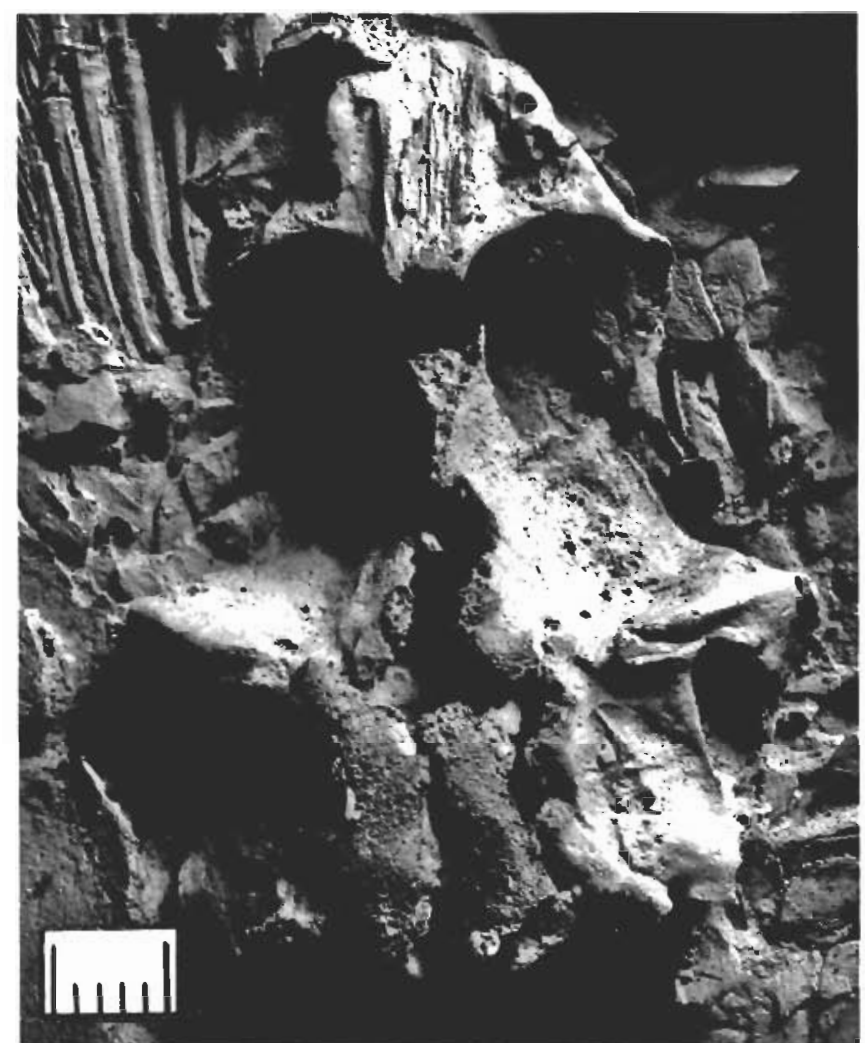

FIGURE 9. Watsonulus eugnathoides, ventral view of braincase (cast, YPM 8990) during its early stages of preparation. Scale equals $5 \mathrm{~mm}$.

missure. If I have interpreted the homologies of the foramen in this region correctly, the canal for the superficial ophthalmic nerves is shorter than in Heterolepidotus, and there is a larger space between the dorsal opening for these nerves and the foramen for the recurrent branch of the facial nerve. There is a relatively large foramen above and in a line with the trigeminofacialis chamber, which is probably for the largest of the ascending branches of the superficial ophthalmic nerves, and this is followed postero-laterally by smaller foramina, presumably for other branches of the same nerves. The posterior myodome is housed in the prootic in a common chamber posterior to the basisphenoid pillar, which is not quite as deep as in Rayner's (1948) "Aspidorhynchus," Macrepistius, or Pholidophorus bechei, but, as in the former two and Heterolepidotus, the foramina for the abducens (VI) and the palatine branch of the facial nerve (VII) lie on the posterior wall of the anterior part of the myodome. Directly dorsal to the antero-lateral opening of the myodome is the foramen for the oculomotor nerve (III), and dorsal to that is first the foramen for the profundus nerve and then the foramen for the trochlear nerve (IV).

In posterior view (Fig. 11), the neurocranium appears sutureless, although the demarcation between the

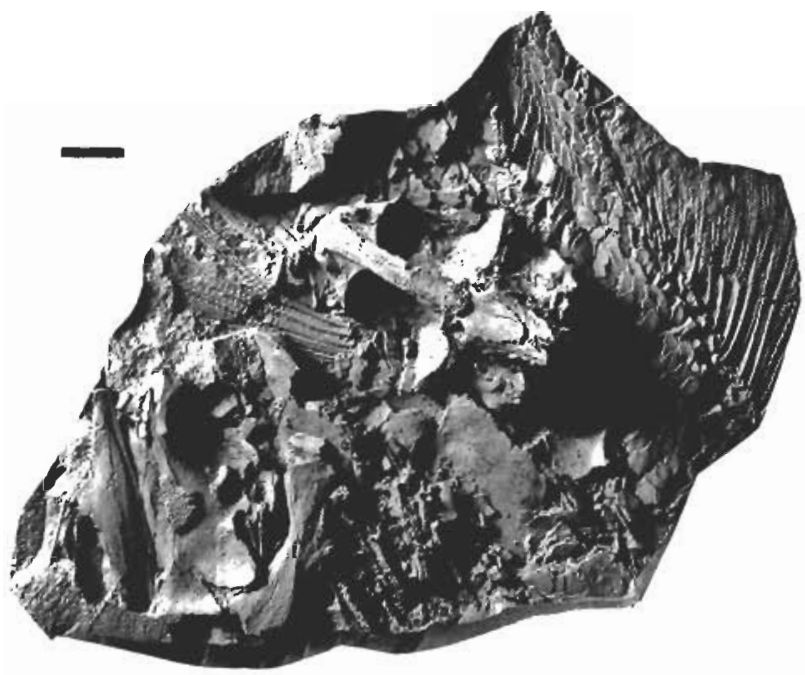

FIGURE 10. Watsonulus eugnathoides, ventral view of cast YPM 8990 after final preparation. Scale equals $5 \mathrm{~mm}$.

skull roofing bones and the neurocranium is clear. The post-temporal fossa is of the same form as in Heterolepidotus, although not as deep, extending only slightly anterior to the posterior edge of the surface of the dermopterotic. As in Heterolepidotus, the latter bone forms the dorso-lateral surface of the fossa, with the rest of the fossa being formed by the epioccipital and probably the pterotic. There is no sign of a separate supraoccipital. The notochordal canal is large and, as already alluded to, not filled with calcified cartilage.

\section{Skull Roof}

As described by Piveteau (1935) and Lehman (1952), Watsonulus has a skull roof showing all the elements seen in most holosteans (Lehman, 1952), notably Parasemionotus, Broughia, Caturus, Heterolepidotus, Macrepistius, Furo and Amia (Fig. 18). There are paired nasals, frontals, parietals, dermopterotics, supratemporals and post-temporals (Figs. 1-4, 6, 7). All the skull-roof bones show a delicate but dense covering of tubercles and ridges (Figs. 4, 7). Like Caturus (SaintSeine, 1949) and Patterson's (1975, fig. 137) undetermined parasemionotid, but apparently unlike Heterolepidotus, Furo and Macrepistius, Watsonulus has a variable, relatively large diamond-shaped fenestra on the anterior part of the skull roof. The fenestra is surrounded by the nasals and anterior portions of the frontals through which the ethmoidal ossifications were exposed (Figs. 2, 14), as described by Piveteau (1935). There is no sign of a median element comparable to the palaeonisciform postrostral or the teleostean rostral (Patterson, 1973, 1975) in this space in any of the specimens I have had access to.

The nasals (Figs. 2, 4) are very large and rectangular, being about one-third the length of the frontals. In some specimens (YPM 8894, 8892) they appear shaped 


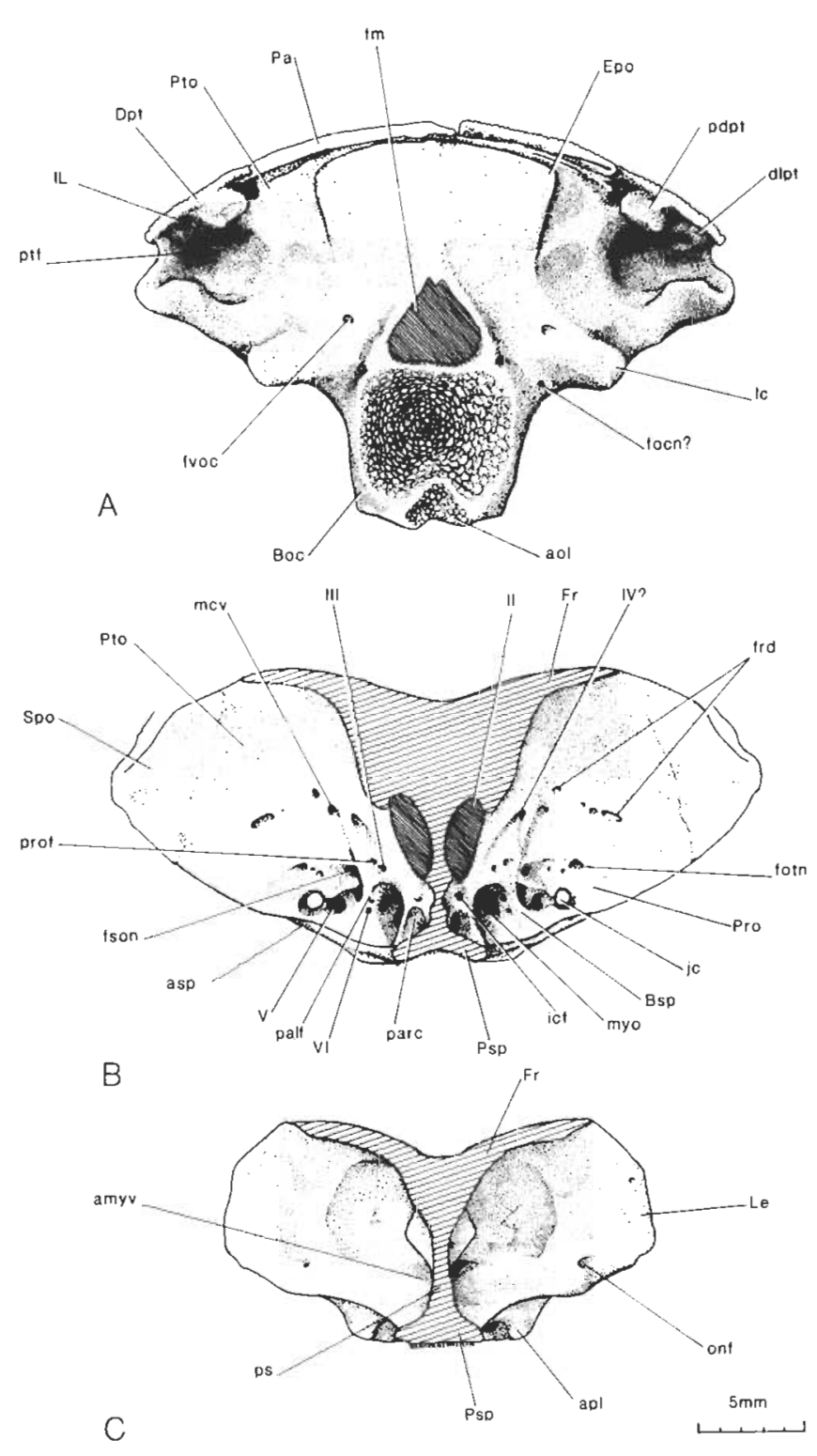

FIGURE 11. A, Posterior view of braincase of Watsonulus eugnathoides. Based on YPM 8989, 8990, 8994, 8995. B, View from just behind the basipterygoid processes, looking posteriorly. Based principally on YPM 8991, 8992. Canal for nerve I not shown because drawings are from casts, cut into pieces. C, View from near middle of orbit, looking anteriorly. Based on Y PM 8990. Abbreviations: I, foramen for olfactory tracts; II, optic fenestra; III, foramen for occulomotor nerve; IV, foramen for trochlear nerve; $\mathbf{V}$, foramen for trigeminal nerve; VI, foramen for abducens nerve; amyv, anterior myodome; aol, area of origin of aortic ligament; apl, articular facet for palatoquadrate complex; asp, ascending wing of parasphenoid; Boc, basioccipital; bpt, basipterygoid process; Dpt, dermopterotic; dlpt, descending lamina of dermopterotic; Epo, region of epiotic; fica, foramen for internal carotid artery; fm, foramen magnum; focn, foramen for occipital artery; fof, foramen for olfactory branch of palatine nerve; fpsa, foramen for efferent pseudobranchial artery; Fr, frontal; frd, foramen for ascending branch of superficial ophthalmic nerves; fson, foramen of superficial ophthalmic nerves; fvoc, foramen of tributary of posterior cerebral vein almost exactly like Patterson's (1975, fig. 137) undetermined parasemionotid (Fig. 4). On the ventral surface there is a weak ridge marking the course of the supraorbital canal as seen on the dorsal surface (Fig. 2); if interpreted as figured by Patterson (1975), this canal would connect with the ethmoidal commissure just lateral to the anterior nostril. The posterior nostril is just lateral to the contact between the nasal and the frontal, if interpreted in the same way (Fig. 2).

The frontals (Figs. 2, 4, 7, 14) are the largest skullroof elements and appear to be somewhat broader than as described by Piveteau (1935) or Lehman (1952), their greatest width being about half their length. The suture between them ranges from sinuous to strongly digitate. On the ventral surface of the frontal, the infraorbital canal is traced out by a ridge bearing a small descending lamella on its posterior half, which lies against the pterosphenoid.

The parietals (Figs. 2, 4, 7, 14) are smaller than the dermopterotics and are usually asymmetrical, with their median suture displaced to the left or right, making one parietal about twice the size of the other; the contact between the two parietals is a simple overlap, but both the contacts between the parietals and the frontals and the parietals and the dermopterotics are digitate.

The dermopterotics are squarish and shaped much as in Macrepistius (Schaeffer, 1960) and Heterolepidotus (Brough, 1939), but, unlike these two genera, over half of the medial edge of the bone is in contact with the frontal (Figs. 2, 4, 7, 14). On the anterior edge of the bone is an excavation into which the dermosphenotic fits.

The supratemporals (Figs. 2,4) are of the usual triangular holostean shape. Their acute apexes touch at midline, and their anterior edges overlap a narrow portion of the neurocranium and narrow portions of the parietals and dermopterotics.

Four canal-bearing infraorbitals (not including the dermosphenotic) form the posterior and ventral margin of the orbit (Fig. 1). The first or lacrymal is triangular and about as large as the third. The second is little more than a tube around the infraorbital canal. The third is again triangular, while the fourth is, again, little more than a tube. There are two anamestic supraorbitals; the anterior one is the longer and seems to be in contact with the antorbital as well as with the first infraorbital.

The antorbital (Figs. 1, 2) has the same shape as

in exoccipital; Ic, intercalar; icf, ascending foramen of internal carotid artery; IL, lateral line; jc, jugal canal; Le, lateral ethmoid; mcv, foramen of middle cerebral vein; myo, posterior myodome; onf, orbitonasal foramen; Pa, parietal; parc, opening of parabasal canal; pdpt, posterior process on dermosphenotic; Pro, prootic; prof, foramen for profundus nerve; ps, preorbital septum; Psp, parasphenoid; ptf, post-temporal fossa; Pto, pterotic; Spo, sphenotic. 
those described by Patterson (1975) for his undetermined parasemionotid and by Bartram (1975) for Ophiopsis. It is roughly " $\mathrm{L}$ "-shaped, with a long rostral process carrying the ethmoidal commissure. The rostral is very small, again resembling that bone in Patterson's (1975, fig. 137) Greenland form.

\section{Dermal Upper Jaw}

Paired premaxillae, maxillae, and supramaxillae make up the dermal upper jaw (Figs. 1, 4, 6, 7). The basic shape of the premaxilla is similar to that in Ophiopsis and Patterson's (1975) Greenland parasemionotid; this shape is not like that seen in other described holosteans. There is, however, a rather close correspondence in shape to that bone in Polypterus (Allis, 1922), although in Polypterus it does carry a sensory canal. There are about seven to nine small pointed teeth. The premaxilla is molded to the surface of the ethmoidal ossifications (Fig. 6). A lateral, postero-dorsally directed lamina of bone coats the lateral surface of the ethmoidal ossifications, and a posteromedially directed lamina of bone floors the ventrolateral surface of the nasal capsule. In lateral view (Fig. 6) it is thus the lateral lamina of bone which is the largest, as in Polypterus, not the lamina flooring the nasal capsule as in most other holosteans, such as $\mathrm{Amia}$, Lapidotes or Acentrophorus (Patterson, 1975). The dentigerous portion of the premaxilla is the thickest part of the bone and is oriented more or less as in Amia. Only the dentigerous portions of the premaxillae meet in midline. Otherwise, the premaxillae are separated by a large trough that was probably filled with cartilage during life (Figs. 7, 14); this cartilage presumably formed a septum between the nasal capsules and may be homologous to the mesethmoid of pholodophorids (Patterson, 1975). In specimens in which the premaxilla is in firm articulation with the ethmoidal ossifications there is a trough running between the ventral surfaces of the bones into which the medial articulatory process of the maxilla fits. Unlike in Amia, most of this trough appears not to have been roofed over by palatal bones.

The maxilla is almost as long as the mandible, with its posterior border about one orbit length behind the eye. The bone bears about 80 to 90 small teeth and the tooth-bearing portion is covered by the same type of fine ornamentation as the skull roof (Fig. 4). There is a long, simple antero-medial process on the maxilla, which articulates with the premaxilla and ethmoidal ossifications. This articulatory process is striated from front to back.

The single supramaxilla (Figs. 1,4) is slightly less than one-half the length of the dentigerous portion of the maxilla and is covered by the same type of sculpture as the maxilla.

\section{Lower Jaw}

The long, low mandible (Figs. 12,14) is very similar to that of Amia, except that the degree of ossification is very much greater in Watsonulus. Externally, the tooth-bearing bones of the lower jaw consist of an elon- gate dentary bearing more than 36 pointed teeth. Internally, it consists of a chevron shaped prearticular and a series of coronoids, all of which bear hundreds of very small, densely packed teeth. The surrangular is relatively large and posteriorly placed. The angular and articular are large, with the latter not subdivided into individual ossifications. There are two articular surfaces: the usual deep, concave surface for the quadrate condyle and a more posteriorly placed convex surface for the symplectic (Figs. 12, 17). Finally, there is a robust, elongate meckelian and/or mentomeckelian bone which continues from the articular forward to the symphysis. Dermal sculpture on the mandible resembles that on the maxilla, but is absent from the portion of the lower jaw which was covered by the maxilla when the mouth was closed (Fig. 12).

\section{Opercular Series}

As described by Piveteau (1935), Lehman (1952) and Gardiner (1967), Watsonulus has the type of oval preoperculum (Figs. 1, 4) characteristic of some other parasemionotids such as Ospia (Stensiö, 1932). Internally, the preoperculum is thickened along its posterior edge, with the thickened portion resembling the entire preoperculum of other holosteans such as Amia. This thickened edge lies lateral to the hyomandibular and symplectic in life. The ventral edge of the preoperculum is notched for the quadratojugal. The operculum (Figs. 1, 4) is the usual large D-shaped bone and is almost as long as high. The suboperculum is relatively large, nearly two-thirds the size of the operculum. The interoperculum is relatively small and triangular. There are at least twelve branchiostegals (Piveteau, 1935, says 14), the most posterior of which is the largest (Figs. 3, 15). As in Amia, this latter branchiostegal does not have a pointed anterior process. The most anterior element in the branchiostegal series is deeper than the subsequent ones and appears to be a lateral gular (Figs. $3,15)$. There is only one relatively small, oval, median gular.

\section{Palate}

Bones of the palatoquadrate complex (Fig. 13) include the quadrate (discussed separately below), metapterygoid, ectopterygoid, entopterygoid, autopalatine, dermopalatine, and possibly accessory palatines. The autopalatine, entopterygoid, and metapterygoid are definitely intimately sutured to each other (seen best in YPM 8995), and it is difficult to make out the boundaries of the individual bones in most specimens. The ectopterygoid, entopterygoid, and metapterygoid bear on their medial surfaces raised tooth patches with very numerous, very small teeth. These tooth patches are largest on the ectopterygoid and smallest on the metapterygoid, and the proportion of each bone so covered decreases in the same order. It should be noted that the small, raised tooth patch on the metapterygoid might be a separate bone and thus could be a dermometapterygoid which, according to Jarvik (1980), is present in Amia. There are a few larger teeth on the 


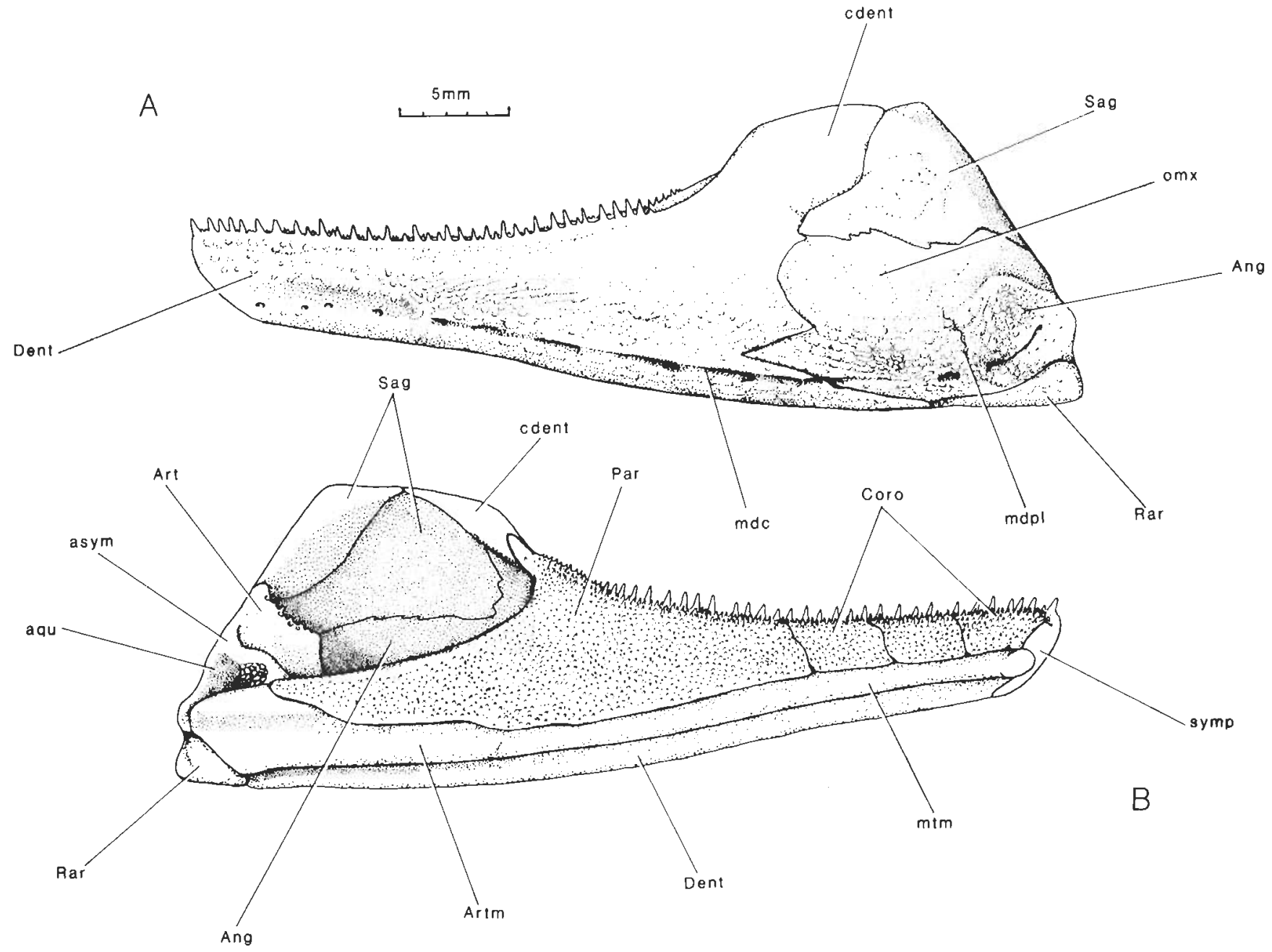

FIGURE 12. Lower jaw of Watsonulus eugnathoides in lateral (A) and medial (B) views, based on YPM 8990, 8994, and 8995. Abbreviations: Ang, angular bone; aqu, articular area for quadrate; Artm, articular-meckelian; asym, articular area for symplectic; cdent, portion of dentary involved in coronoid process; coro, coronoids; Dent, dentary; mdc, mandibular canal; mdpl, mandibular pit line; mtm, mentomeckelian bone; omx, area of overlap of maxilla on mandible; Par, prearticular; Rar, retroarticular; Sag, surangular; symp, symphysial region of mandible.

anterior edge of the ectopterygoid, in line with the larger of the teeth on the dermopalatine. The dermopalatine and accessory palatines are not seen in place in any of the specimens of Watsonulus at my disposal, although they do show up displaced near the anterior edge of the palatoquadrate, with a clear gap remaining anterior to the ectopterygoid and entopterygoid tooth patches (Fig. 13). The autopalatine is a robust bone with a distinct flat lateral surface and a well ossified articular surface for the ethmoidal ossifications.

The parasphenoid has already been discussed with the braincase.

Unlike in other holosteans, the vomers (Fig. 8) are very weakly attached to the parasphenoid and are displaced in all but one specimen available to me (Figs. $5,10)$. They are small and do not appear to suture with the parasphenoid. In these respects they resemble the poorly differentiated vomers found in some chondrosteans (Patterson, 1975). Each vomer bears about eight small teeth.

\section{Hyomandibular, Symplectic, Quadrate and Ceratohyal}

The hyomandibular is a large bone, nearly four-fifths the length of the braincase (Fig. 13). It is hourglassshaped, narrow, bears a prominent opercular process, and is pierced by a foramen for the hyoidean branch of nerve VII. As in Patterson's undetermined parasemionotid (1973, fig. 23), the symplectic is very large and bears an articulatory head for the mandible. In contrast to Amia there are no membranous outgrowths on the symplectic. The quadrate is triangular and is 


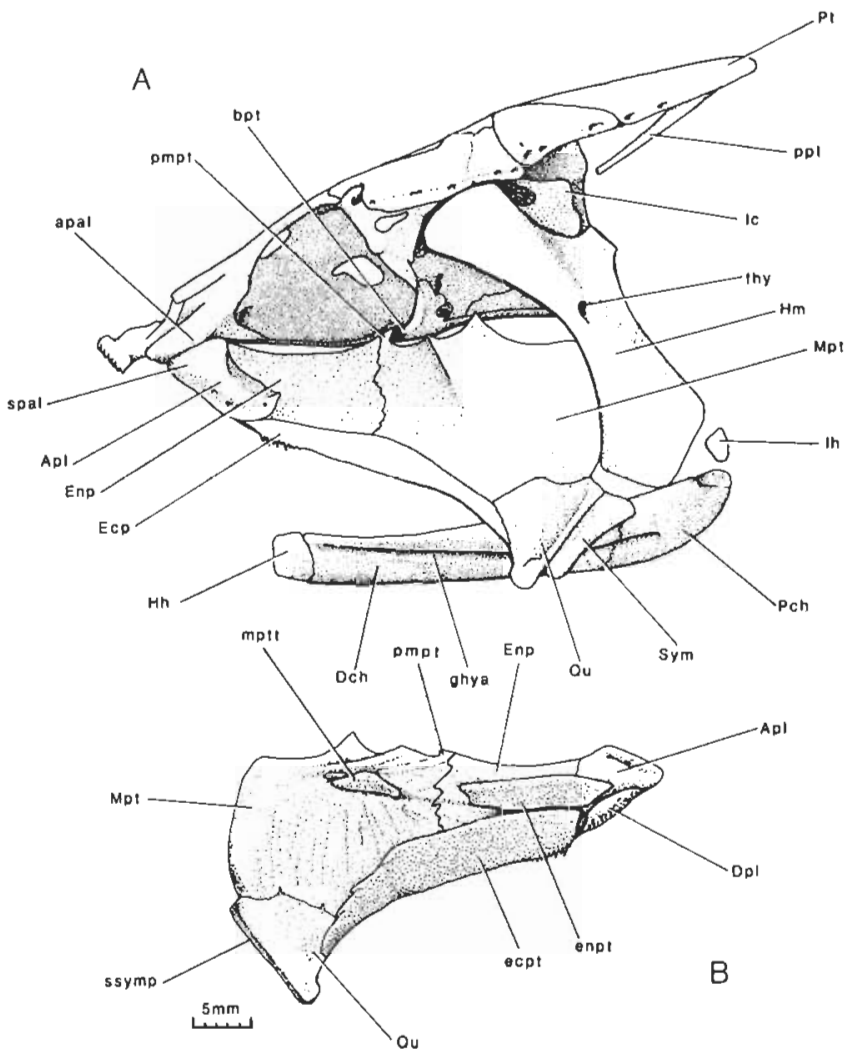

FIGURE 13. Watsonulus eugnathoides: A, Reconstruction of palatoquadrate, hyomandibular, ceratohyal-hypohyal, and braincase in lateral view, based principally on YPM 8990 and $8995 ; \mathbf{B}$, medial view of palatoquadrate complex, based on YPM 8995. Abbreviations: apal, articular facet for palatoquadrate complex; Apl, autopalatine; bpt, basipterygoid process; Dch, distal ceratohyal; Dpl, dermopalatine; Ecp, ectopterygoid; ecpt, tooth patch on ectopterygoid; Enp, entopterygoid; enpt, tooth patch on entopterygoid; fhy, foramen for hyomandibular nerve; ghya, groove for afferent hyoidean artery; Hh, hypohyal bone; Hm, hyomandibular; Ic, intercalar; Ih, interhyal; Mpt, metapterygoid; mptt, dermometapterygoid or tooth patch on metapterygoid; Pch, proximal ceratohyal; pmpt, process on metapterygoid for ligamentous attachment to basipterygoid process; ppt, post-temporal process; Pt, post-temporal; Qu, quadrate; spal, surface on autopalatine for articulation with ethmoidal region; ssymp, surface for attachment of symplectic; Sym, sympletic.

sutured to the ectopterygoid and metapterygoid (Fig. 14). Posteriorly there is a shallow groove for the symplectic.

On its postero-lateral edge, the quadrate bears a ridge which becomes a flange antero-ventrally (Fig. 13). Patterson (1973) observed this in his Greenland form and concluded that it could be the homologue of the quadratojugal. In YPM 8990 I was able first to observe this flange and then to uncover a small squarish bone lateral to it (Figs. 1, 15). This small bone fits in the notch in the preoperculum and bears dermal sculpture. This bone matches the type of plate-like quadratojugal seen

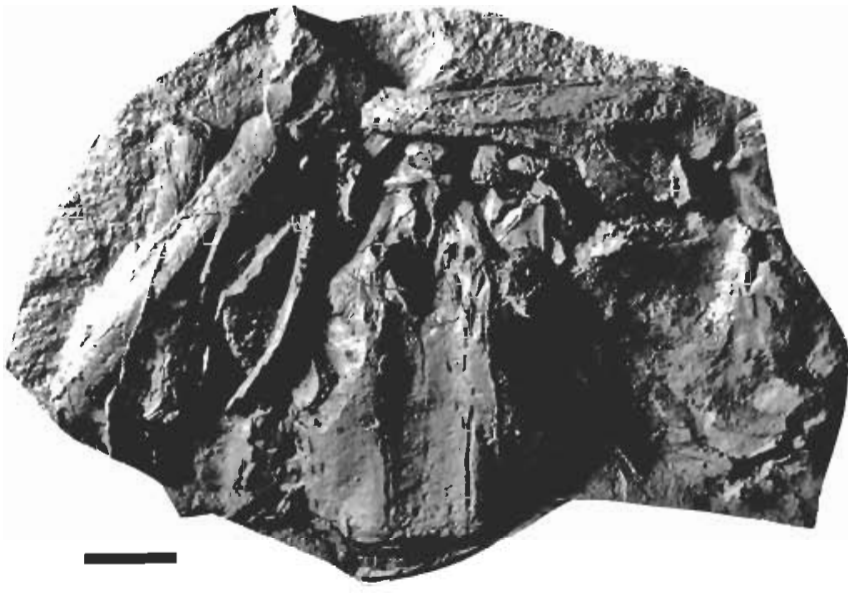

FIGURE 14. Watsonulus eugnathoides, dorsal view of cast YPM 8995. Scale is $5 \mathrm{~mm}$.

in some chondrosteans (Figs. 15, 18), such as Pteronisculus (Nielsen, 1942) and Cheirolepis (Pearson and Westoll, 1979), and shows that the flange on the quadrate is not a fused and reduced quadratojugal. Such an element was described in Ospia by Stensiö (1932).

There are paired hypohyals, distal ceratohyals and proximal ceratohyals, in the usual actinopterygian manner (Figs. 5, 13). The proximal and distal ceratohyals are closely articulated and together are hourglass-shaped. The lateral surface of the hypohyal, and the distal and proximal ends of the ceratohyal are deeply grooved for the afferent hyoid artery, as in Pteronisculus (Nielsen, 1942).

\section{Dermal Shoulder Girdle}

The shoulder girdle of Watsonulus is extremely unusual for what otherwise seems to be a neopterygian

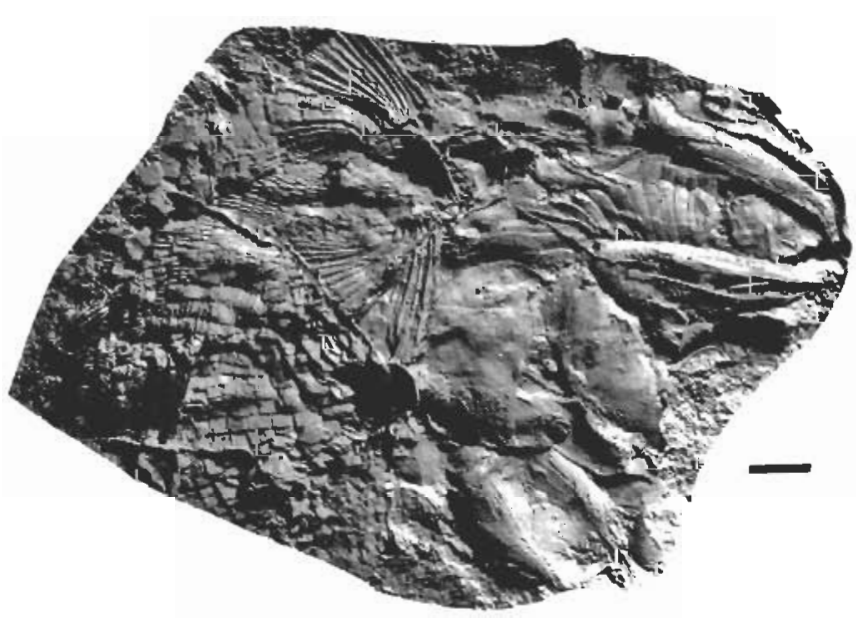

FIGURE 15. Watsonulus eugnathoides, ventral view of cast YPM 8996. Scale is $5 \mathrm{~mm}$. 


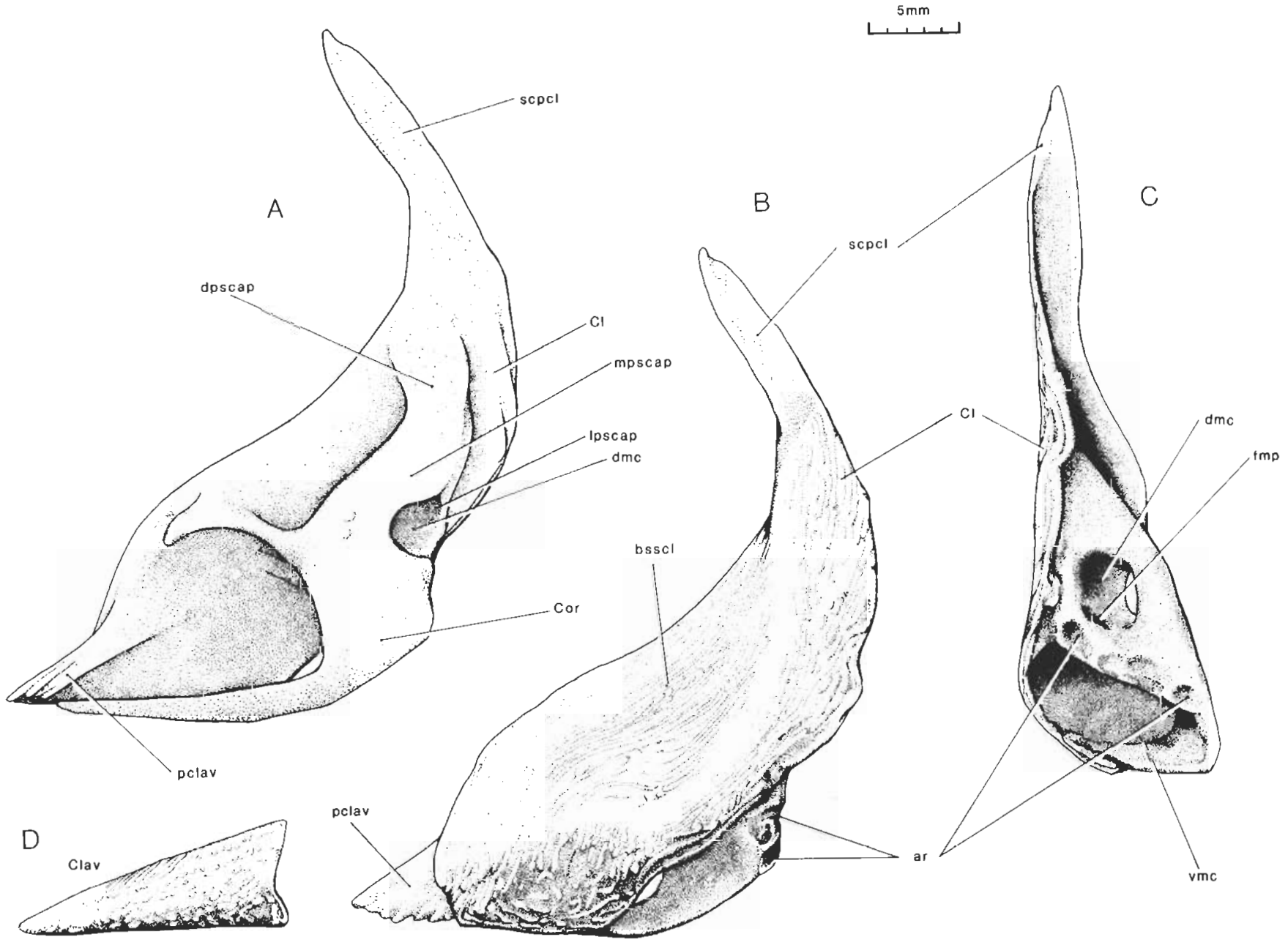

FIGURE 16. Shoulder girdle of Watsonulus eugnathoides based on YPM 8994, in (A) medial view, (B) lateral view, and (C) posterior view; (D) is the clavicle. Abbreviations: ar, articular area for radials; bsscl, portion of cleithrum bordering on branchial chamber; Cl, cleithrum; Cor, coracoid portion of endoskeletal shoulder girdle; dmc, dorsal muscle canal; dpscap, dorsal process of scapular region of endoskeletal shoulder girdle; fmp, middle canal of mesocoracoid arch; lpscap, lateral process of scapular region of endoskeletal shoulder girdle; mpscap, medial process of scapular region of endoskeletal shoulder girdle; pclav, process for articulation of clavicle; scpcl, portion of cleithrum passing medial to supracleithrum; vmc, ventral muscle canal.

(Fig. 16). There are the usual holostean post-temporal, supracleithrum, cleithrum and postcleithral bones, but, in addition, a completely unreduced clavicle of the palaeoniscoid type. The clavicle is an elongate triangle cylindrically concave medially, and is covered laterally with the same type of dermal ornamentation that is present on the skull and cleithrum.

The cleithrum has the usual simple $C$ shape, and is covered on its lateral surface with fine dermal ornamentation (Figs. 5, 16). Anteriorly, the cleithrum ends in a sculptureless process which is completely covered by the clavicle in articulated specimens (Figs. 1, 3, 16). In ventral view, the arrangement of elements of the pectoral girdle and the elements of the branchiostegal series and gular look very much like in Pteronisculus
(Nielsen, 1942) and other chondrosteans. The dorsalmost portion of the dorsal limb of the cleithrum also lacks sculpture; that portion underlies the supracleithrum.

The supracleithrum has the same shape and relationship to the cleithrum and post-temporal as in Amia, although the bone is relatively larger in Watsonulus (Figs. 1, 4, 18). The lateral surface is covered by dermal sculpture of the same type as the cleithrum. Unfortunately, the supracleithrum is obscured in medial view in all the specimens I have looked at.

The post-temporal (Figs. 2, 4) is very large, about twice as long as the supratemporal, and meets its fellow at the midline. As in Amia, the post-temporal has an antero-ventrally directed process which was ligamen- 
tously attached to the intercalar. This process arises from the middle of the ventral surface of the bone near its lateral edge (Fig. 13).

\section{Endochondral Bones of the Shoulder Girdle}

The endochondral portion of the shoulder girdle is very well ossified and well displayed in several specimens (Figs. 5, 16). Remarkably, there are no apparent qualitative differences between the endochondral shoulder girdle of Watsonulus and teleosts such as Elops, and few differences with chondrosteans such as Acipenser (Jessen, 1972). Most important among the teleost- or chondrostean-like features are the large and open arch created by the medial process of the scapular, and the antero-lateral portion of the coracoid; there is thus no pontiform element of Jessen (1972, Spangenstück) found in both Amia and Lepisosteus. In addition, there is a long anterior process on the coracoid which extends to the tip of the cleithrum and thus into the area overlapped by the clavicles, reminiscent of Acipenser (Jessen, 1972). This process is flared into a horizontal plate at its contact with the clavicle.

\section{RELATIONSHIPS OF WATSONULUS}

Watsonulus eugnathoides occupies a critical position within the Neopterygii of Patterson (1973) because it shares two primitive characters with chondrosteans that are derived in other neopterygians. These are 1) unreduced clavicles, and 2) a preoperculum with a broad dorsal limb. Because of these shared primitive characters, Watsonulus and some other parasemionotids are crucial to establishing the polarity of characters in other groups of neopterygians. Below, I review the characters which ally Watsonulus to the other neopterygians and discuss the distribution of the primitive characters shared with chondrosteans. Then, I discuss the derived characters which unite the other neopterygians. Finally, I use the framework provided by the position of Watsonulus relative to other neopterygians to try to determine relationships of gars, Amia, teleosts and certain fossil holosteans. I contend that Watsonulus is vital to assessing the relationships of living actinopterygians if regarded as a terminal taxon, the structure of which tests hypotheses of character combinations and relationships based on purely osteological characters in living fishes.

The following six characters are shared by Watsonulus and at least primitive members of other neopterygian groups, and are derived with respect to chondrosteans: 1) interoperculum present-chondrosteans lack this element; 2) maxilla free, with internal articular head - the chondrostean maxilla is firmly attached to the cheek and palatoquadrate; 3 ) supramaxilla present - there is no supramaxilla in any chondrostean; 4) vomers differentiated and molded to the underside of the ethmoid region - chondrosteans either completely lack any toothed bones in the position of the vomers, or have small bones present in the area, but these are not so firmly attached or regularly shaped as in neopte- rygians; 5) coronoid process made up of a portion of the dentary, surrangular, and angular-there is no such compound structure in chondrosteans; and 6) vertical suspensorium-chondrosteans have an oblique suspensorium or at least the hyomandibular has a strong oblique articular surface on the braincase. In addition, there is one more character absent in most chondrosteans but present in Watsonulus and other neopterygians: the post-temporal fossa. According to Patterson (1975), this structure is present in a rudimentary form in the chondrostean Perleidius. Patterson (1973) and Wiley (1976) list two other characters of neopterygians: 1) clavicles lost by reduction to a series of denticlebearing ossicles - in chondrosteans there are large clavicles which lap onto the cleithrum and bear dermal sculpture; and 2) preoperculum with a narrow dorsal limb-the preopercular of chondrosteans is expanded dorsally (Fig. 18). In Watsonulus, both characters remain in the chondrostean condition. Patterson (1977) concluded that "In Pholidophorus, ... the clavicle is represented by two denticulate plates which resemble those in Amia except both are flat and do not project freely like the serrated appendage in Amia." The pholidophorid clavicle is the largest and least reduced known in neopterygians, yet it is clearly more reduced than in Watsonulus where the bone still bears dermal ornamentation. The clavicle is further reduced in Furo and Caturus (Patterson, 1977; Bartram, 1977), and a bit more reduced in Amia. In gars and semionotids (sensu Olsen and McCune, in prep.) the clavicle is represented by a small series of ossicles in the former and by a very small denticulate splint in the latter. The pattern of reduction of the clavicle in these groups suggests that initiation of reduction occurred in forms more advanced than Watsonulus. If we assume that reduction of the clavicles and of the width of the dorsal limb of the preopercular occurred only once within the neopterygian clade, then the condition in other neopterygians represents synapomorphies uniting those fishes in a monophyletic group, and Watsonulus must be the sister-group of that group (Fig. 19).

Characters shared by Watsonulus and neopterygians that have reduced clavicles and a reduced dorsal limb of the preopercular must be primitive for neopterygians if the foregoing statements are correct and if the characters are not homoplasic. Crucial among these primitive characters is the nature of the jaw joint. As pointed out by Patterson (1973), there are three basic styles of jaw joints among the neopterygians.

1) In Amia and Watsonulus (Fig. 17C, B) the symplectic takes part in the jaw joint as does the quadrate. There are special articular surfaces on the mandible for both these bones. In Watsonulus the quadratojugal is small, separate and quadrangular, as it is in chondrosteans. In Amia there is no separate quadratojugal.

2) In gars (Fig. 17F) the symplectic ends on the quadratojugal before it reaches the quadrate. The quadratojugal is a large splint-like bone which supports the quadrate condyle, but does not take part in the jaw joint. Patterson (1973) has shown that semionotids 

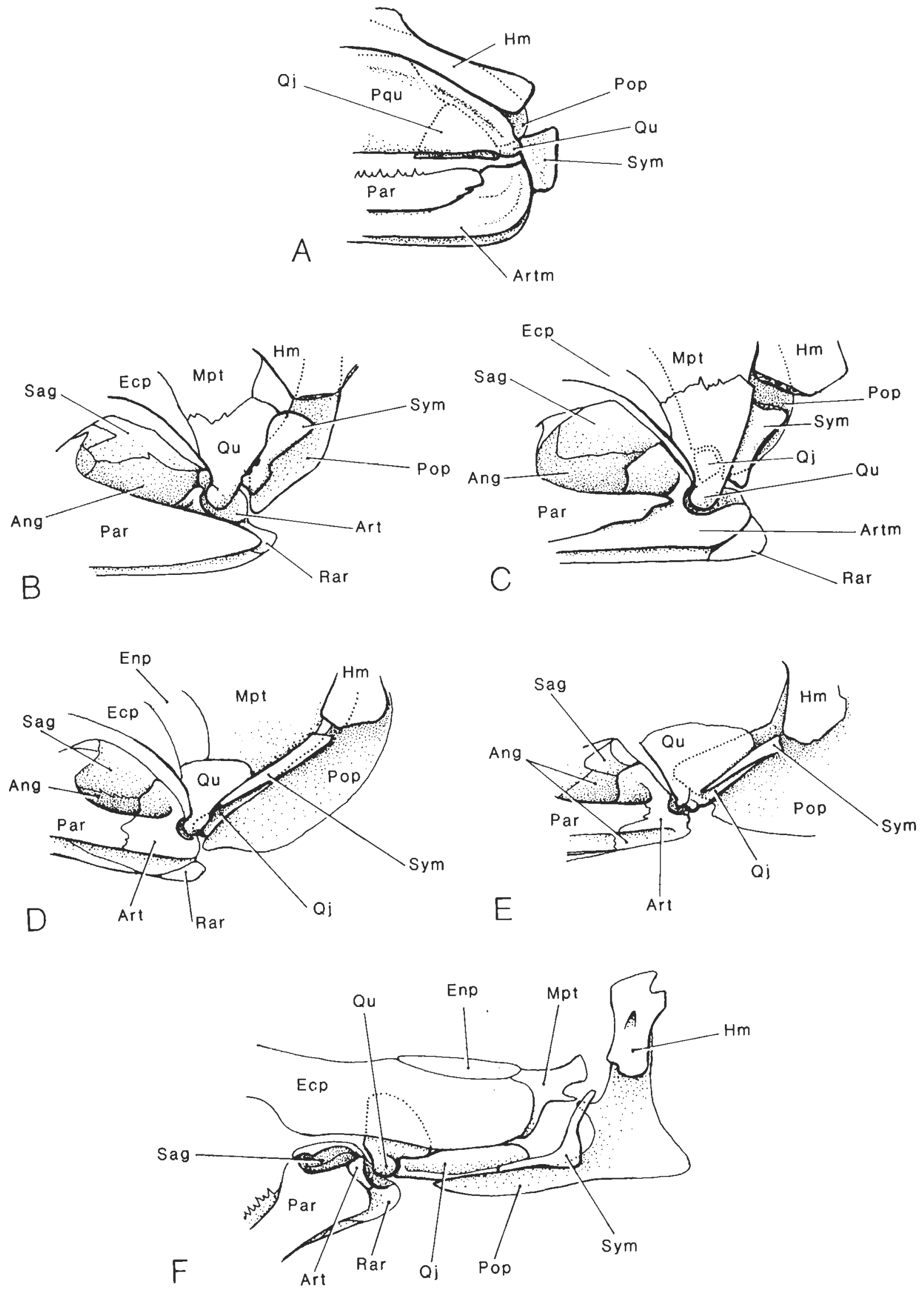
(sensu Olsen and McCune, in prep.) and dapediids (sensu Wenz, 1968) possess a jaw joint similar to gars. The quadratojugal is free and supports the quadrate condyle against the preoperculum, as in gars. The symplectic is excluded from the jaw joint, but ends on the medial surface of the quadrate. Patterson (1973) concludes that the gar condition is a variant on the semionotid-dapediid jaw-joint plan.

3) In teleosts (Fig. 17E) the basic configuration of the jaw joint resembles that of semionotids and dapediids, and hence gars. The quadratojugal is large and splint-like, and braces the quadrate against the preoperculum; it is, however, fused to the articular region of the quadrate, rather than free (Patterson, 1973). Also, as in semionotids and dapediids, the symplectic does not enter into the jaw joint but ends in a groove between the quadratojugal and the quadrate. Clearly, the teleost condition more closely resembles the gar-semionotid-dapediid condition than it does the Watsonulus-Amia condition (Fig. 17).

Patterson (1973, 1975) and Bartram (1977) have hypothesized that the Amia-style jaw joint is a derived character uniting parasemionotids with $\mathrm{Amia}$, and that the gar condition is the primitive condition for neopterygians. For their hypothesis to be correct, however, either both reduced clavicles and a narrow preoperculum would have to have been developed independently in the Amia-Watsonulus clade and the gar and teleost clades, or the unreduced clavicles and broad preoperculum would have to be atavistic homoplasies in Watsonulus. Neither of these two alternatives is strongly supported, and there is some independent evidence from the nature of the jaw joint in fossil chondrosteans and other fishes that the jaw joint of Watsonulus indeed might be primitive for the Neopterygii.

Nielsen (1942) has described a small but robust symplectic which articulates with the meckelian ossification (as in Amia and Watsonulus) in the chondrostean Pteronisculus (Glaucolepis) (Fig. 17A). According to Nielsen, this bone is not perichondrally lined on the dorsal surface, the hyomandibular is not perichondrally lined on its ventral end, and the two bones are of about the same diameter; they could be part of the same cartilage as in Amia. Nielsen (1949) has also described a less well ossified symplectic in Birgeria and Boreosomus. Specimens of Birgeria from Madagascar available to me show a style of jaw joint very similar to that Nielsen described in Pteronisculus. In YPM 8997 the right symplectic appears in natural position and sits directly in line with, and very close to, the hyomandibular. Neither bone is perichondrally lined on the surfaces where they would meet and the ventral edge of the symplectic is in contact with the posteromedial portion of the meckelian-articular ossification.

In these fossil chondrosteans the symplectic is very different in form from Polyodon and Acipenser. In these latter fish, the symplectic has its own separate cartilage, which might not be homologous with that in Amia or Pteronisculus, and, for that matter, Boreosomus. Without knowledge of the relationships within the chondrosteans, the meaning of the separate sympletic in living forms is ambiguous.

In dipnoans the distal end of the hyomandibular articulates directly with the mandible and there is no separate symplectic; this might be equivalent to the condition in Amia. The hyomandibular articulates with the mandible in many Recent sharks [in which, according to Maisey $(1980,1983)$, the condition is derived], and has a ligamentous connection in many $\mathrm{Re}-$ cent and apparently most ancient sharks. A very close association of the hyomandibular with the jaw joint might be primitive for gnathostomes in general, and a direct joint between the hyomandibular (and/or symplectic) and mandible may be primitive for Osteichthyes in particular.

We can conclude from this discussion that if the broad dorsal limb of the preopercular and the unreduced clavicle of Watsonulus are primitive characters shared with chondrosteans, and reduction of these characters to the condition seen in Amia happened only once within Neopterygii, the nature of the jaw joint of Watsonulus and Amia must be a shared primitive character for neopterygians and possibly for actinopterygians as a whole. The nature of the jaw joint in gars and teleosts must be derived. Amia must, therefore, represent the sister-group of the clade containing both gars and teleosts, and Watsonulus must be the sister-group of the clade containing Amia, gars and teleosts (Fig. 19).

This proposed hypothesis of relationships (Fig. 19) is in dramatic contrast to that proposed by Patterson $(1973,1975)$ and Wiley (1976). They have advanced a hypothesis of relationships for teleosts, Amia and gars, in which Amia and teleosts are more closely related to each other than either is to gars, and gars are hypothesized to be the primitive sister-group of all other neopterygians. This hypothesis rests principally on the assumed primitive condition of a series of prin-

FIGURE 17. Medial views of actinopterygian jaw joints. A, a chondrostean Pteronisculus (adapted from Nielsen, 1942). B, Amia (adapted from Patterson, 1973) C, Watsonulus. D, A semionotid member of the "Semionotus elegans group" (from Olsen and McCune, in prep.). E, A teleost, Pholidophorus (adapted from Patterson, 1973). F, A gar, Lepisosteus (adapted from Patterson, 1973). Abbreviations: Ang, angular; Artm, articular-meckelian; Ecp, ectopterygoid; Enp, entopterygoid; Hm, hyomandibular; Mpt, metapterygoid; Par, prearticular; Pop, preopercular; Pqu, palatoquadrate complex; Qj, quadratojugal; Qu, quadrate; Rar, retroarticular; Sag, surangular; Sym, symplectic. 

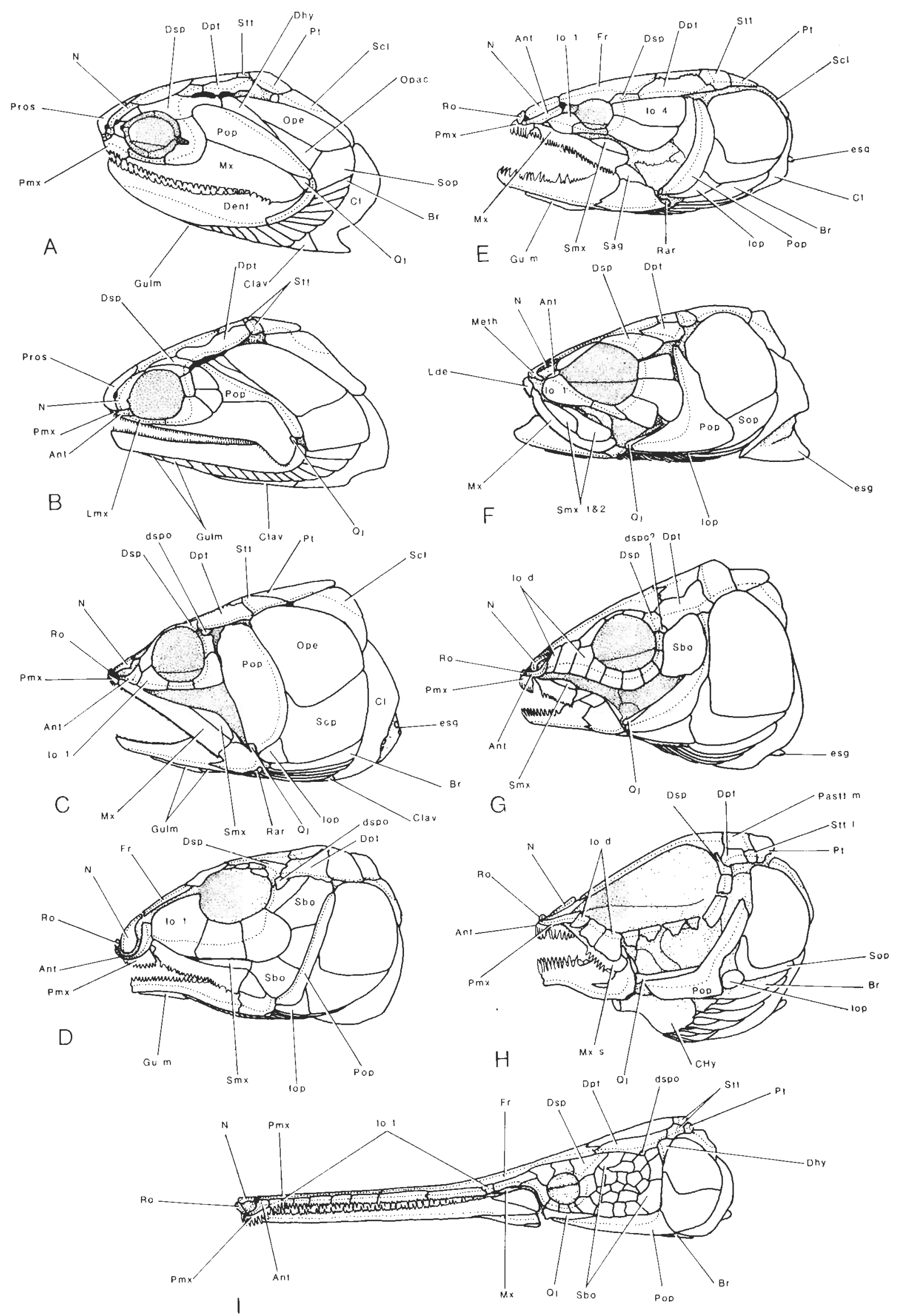


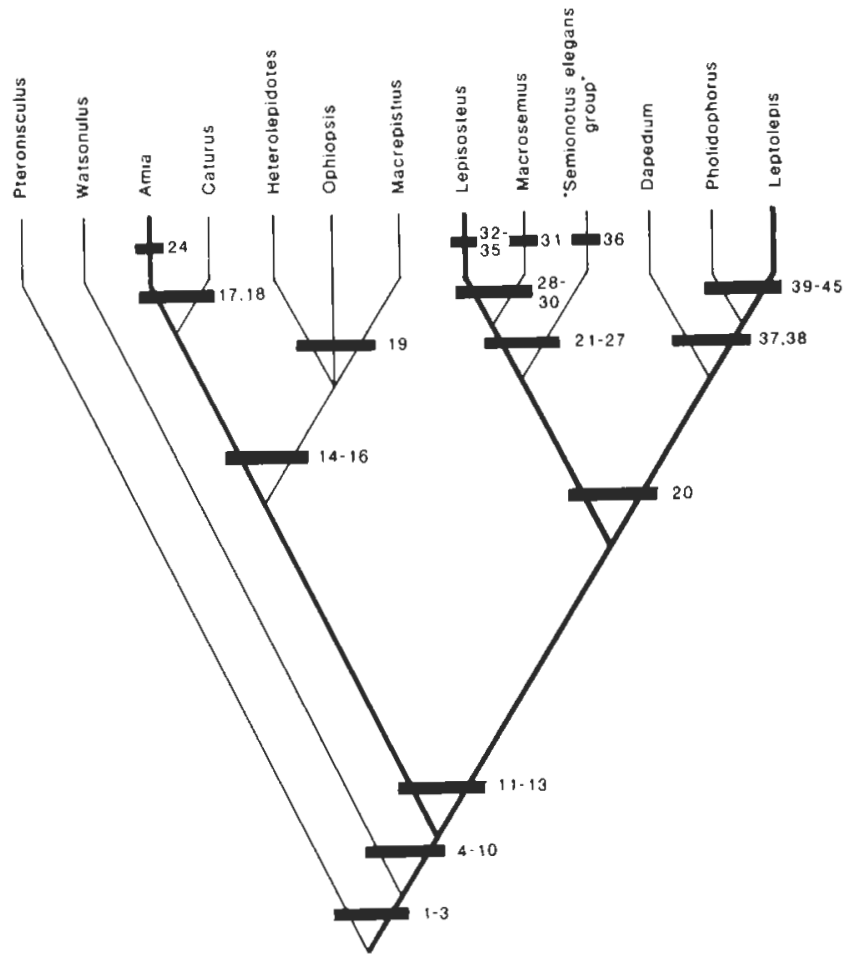

FIGURE 19. Cladistic relationships of various actinopterygians based on the combination of characters seen in Watsonulus. Bars represent synapomorphies at that node. Heavy part of cladogram is three-taxon hypothesis relating living neopterygians with Leptolepis as representative primitive te- leost. Characters 1-3 may be primitive at a level more general than the node they are shown at here. Characters from Olsen and McCune (in prep.), Patterson (1973, 1975), Nielsen (1942), Bartram (1975, 1977), and Wiley (1976). Characters: 1, symplectic in jaw joint; 2 , anterior and posterior myodomes present; 3 , preopercular with broad dorsal margin; 4, vomer differentiated; 5 , lower jaw with compound coronoid process; 6 , suspensorium vertical; 7 , maxilla with internally directed articulatory head present; 8, supramaxilla present; 9, interoperculum present; 10 , post-temporal fossa present; 11, clavicles reduced; 12, preopercular with narrow dorsal limb; 13, vomers moded to underside of ethmoidal region and sutured to the parasphenoid; 14, intercalar with membranous outgrowths of the Amia type; 15, quadratojugal lost; 16, dermosphenotic forms integral part of skull roof; 17, membranous outgrowths on symplectic, binding it to preopercular; 18, opisthotic lost; 19, elongated infraorbitals; 20, symplectic removed from jaw joint, ending blindly on medial face of quadrate; 21, gular lost; 22, intercalar lost; 23, epiotic is modified pterotic; 24 , premaxilla with greatly elongated nasal processes; 25 , only arch of mesocoracoid ossified in shoulder girdle; 26, first infraorbital subdivided; 27 , reduction of ethmoidal ossification to splint; 28, supramaxilla lost; 29, interopercular reduced; 30, supratemporals subdivided; 31, median supratemporal fused with parietal; 32, maxilla loses contact with ethmoidal region; 33, anterior myodome lost; 34, interopercular lost; 35, lepisosteid synapomorphies in Wiley (1976); 36, dorsal ridge scales; 37, internal carotids pierce parasphenoid; 38, median vomer; 39, intercalar with membranous outgrowths of the teleost type; $\mathbf{4 0}$, ural neural arches as uroneurals; 41 , two supramaxillae; 42 , median supraethmoid; 43, free lateral dermoethmoids; 44, myodome extending into basioccipital; $\mathbf{4 5}$, intercalar and prootic forming strut. cipally skeletal characters in gars and on the supposed derived nature of the Amia jaw joint. A complete analysis of the characters used by Patterson and Wiley to support these relationships is given in another paper (Olsen and McCune, in prep.); but, it is clear at this point that their hypothesis of relationships is incompatible with the relationships suggested by the characters found in Watsonulus. Patterson (1973, 1975) uses the hypothesized relationships between the three living groups ( $A$ mia, gars and teleosts) as a foundation on which the relationships of the fossil holostean groups can be built. The relationships suggested after an analysis of Watsonulus provide a different framework (Fig. 19 ), and hence the relationships of other fishes fitted into that framework are rather different from those previously suggested. In Figure 19, I fit several other well known holostean fishes into this new framework. Documentation for the characters of fishes other than

$\leftarrow$

FIGURE 18. Comparisons of actinopterygian skull-bone patterns in lateral view: $\mathbf{A}$, an early chondrostean, Cheirolepis (from Pearson, 1982); B, a later chondrostean, Pteronisculus (from Nielson, 1942); C, Watsonulus; D, a "caturid," Ophiopsis (from Bartram, 1975); E, Amia (from Patterson, 1973); F, a teleost, Allothrisops (adapted from Patterson and Rosen, 1977); G, a semionotid, member of the "Semionotus elegans group" (from Olsen and McCune, in prep.); $\mathbf{H}$, a macrosemiid, Macrosemius (from Bartram, 1977); I, a gar, Lepisosteus (modified from Patterson, 1973, on the basis of a dried skull). Abbreviations: Ant, antorbital; Br, branchiostegal ray; CHy, ceratohyoid complex; $\mathrm{Cl}$, clavicle; Dhy, dermohyal; Dsp, dermosphenotic bone; esg, endoskeletal shoulder girdle; Dpt, dermopterotic; Dsp, dermosphenotic; dspo, exposed portion of sphenotic; Fr, frontal; Gu m, median gular; Gulm, median and lateral gulars; Io 1, Io 4, infraorbitals one and four; Io d, infraorbitals; Io t, tooth-bearing infraorbitals; Iop, interopercular; Lde, lateral dermethmoid; Meth, mesethmoid; Mx, maxillary; Mx s, maxilla without supramaxilla; N, nasal; Opac, accessory opercular; Ope, opercular; Pmx, premaxillary; Pop, preopercular; Pros, postrostral; Pt, post-temporal; Qj, quadratojugal; Ro, rostral; Rar, retroarticular; Sag, surangular; Sbo, anemestic suborbitals; Scl, supracleithrum; Smx, supramaxillary; Smx1\&2, supramaxillae one and two; Sop, subopercular; Stt, supratemporal; Stt 1, lateral supratemporal. 
Watsonulus listed in this cladogram is given in the references cited in the figure and in Olsen and McCune (in prep.). I must stress at this point, however, that my proposed set of relationships based on Watsonulus is only one of a series of reasonable cladograms, and these will be the subject of future papers.

Patterson (1973) has discussed the three possible cladograms which relate Amia, gars and teleosts. It is interesting that of these three cladograms the one suggested by the characters present in Watsonulus is the one hypothesis paleontologists have never seriously proposed. Yet, at this time, I feel it is also the least refuted hypothesis.

Acknowledgments-My warmest thanks are extended to Keith Stewart Thomson, who suggested that I write this paper, and who generously supplied his expertise, guidance and encouragement during the preparation of the manuscript. I am indebted to John Kirsch, Amy McCune, Colin Patterson and, of course, Bobb Schaeffer for many lengthy discussions on systematics in general and on holostean relationships in particular. I thank Richard Boardman for his skill in preparing the Watsonulus specimens, and William Sacco for the photographs used in this paper. Cynthia Banach, Peter Forey, Colin Patterson and Keith Thomson read the manuscript and suggested many changes which substantially improved it. Finally, I thank the Museum of Comparative Zoology of Harvard University for loan of the material. This work is part of a project on Triassic fishes supported by grants from the U.S. National Science Foundation to Keith Thomson (grants DEB 7708412 and DEB 79-21746).

\section{REFERENCES}

Allis, E. P. 1922. The cranial anatomy of Polypterus, with special reference to Polypterus bichir. Journal of Anatomy 56:189-294.

Anderson, H. M. and Anderson, J. M. 1973. A preliminary review of the biostratigraphy of the uppermost Permian, Triassic, and lowermost Jurassic of Gondwanaland. Palaeontologica Africana 21:57-77.

Baird, D. 1951. Latex molds in paleontology. Compass of Sigma Gamma Epsilon 28(4):339-345.

1974. Latex Vormen in der Paläontologie. Museologia 2:41-43.

Bartram, A. W. H. 1975. The holostean fish genus Ophiopsis Agassiz. Zoological Journal of the Linnean Society of London 56:183-205.

— 1977. The Macrosemiidae, a Mesozoic family of holostean fishes. Bulletin of the British Museum (Natural History), Geology 29(2):137-234.

Beltan, L. 1968. La faune ichtyologique de l'Eotrias du N. W. Madagascar: le néurocrâne. Centre National de la Recherche Scientifique, Paris, 135 pp.

Brough, J. 1939. The Triassic Fishes of Besano Lombardy. British Museum (Natural History), London, 117 pp.

Gardiner, B. G. 1960. A revision of certain actinopterygian and coelacanth fishes, chiefly from the lower Lias. Bulletin of the British Museum (Natural History), Geology 4:239-384.

1967. The significance of the preoperculum in ac- tinopterygian evolution. Journal of the Linnean Society of London (Zoology) 47:197-209.

Jarvik, E. 1980. Basic Structure and Evolution of Vertebrates, Vol. 1. Academic Press, London, 562 pp.

Jessen, H. 1972. Schultergürtel und Pectoralflosse bei Actinopterygiern. Fossils and Strata 1:1-101.

Lehman, J. P. 1952. Etude complémentaire des Poissons de l'Eotrias de Madagascar. Kungliga Svenska Vetenskapsakademiens Handlingar (4) 2 (6):1-201.

Maisey, J. G. 1980. An evaluation of jaw suspension in sharks. American Museum Novitates no. 2706:1-17.

1983. Cranial anatomy of Hybodus basanus Egerton from the Lower Cretaceous of England. American Museum Novitates no. 2758:1-64.

Nielsen, E. 1942. Studies on Triassic fishes from East Greenland. I. Glaucolepis and Boreosomus. Meddelelser om Grønland 138:1-403.

- 1949. Studies on Triassic fishes from East Greenland. II. Australosomus and Birgeria. Meddelelser om Gronland 146:1-309.

Nybelin, O. 1966. On certain Triassic and Jurassic representatives of the family Pholidophoridae s. str. Bulletin of the British Muscum (Natural History), Geology 11: $351-432$.

Olsen, P. E. and McCune, A. R. (in prep.). Morphology of Early Jurassic age semionotid fishes from the Newark Supergroup of eastern North America with comments on the family Semionotidae and description of a new genus.

Patterson, C. 1973. The interrelationships of holosteans; pp. 233-305 in Greenwood, P. H., Miles, R. S. and Patterson, C. (eds.), Interrelationships of Fishes. Academic Press, London.

- 1975. The braincase of pholidophorid and leptolepid fishes, with a review of the actinopterygian braincase. Philosophical Transactions of the Royal Society of London (B) 269:275-579.

1977. Cartilage bones, dermal bones, and membrane bones, or the exoskeleton versus the endoskeleton; pp. 77-121 in Andrews, S. M., Miles, R. S. and Walker, A. D. (eds.), Problems in Vertebrate Evolution. Linnean Society of London, Symposium Series No. 4, Academic Press, London.

1982. Morphology and interrelationships of primitive actinopterygian fishes. American Zoologist 22:241295.

- and Rosen, D. E. 1977. Review of ichthyodectiform and other Mesozoic teleost fishes and the theory and practice of classifying fossils. Bulletin of the American Museum of Natural History 158:81-172.

Pearson, D. M. 1982. Primitive bony fishes, with especial reference to Cheirolepis and palaeonisciform actinopterygians. Zoological Journal of the Linnean Society of London 74:35-67.

___ and Westoll, T. S. 1979. The Devonian actinopterygian Cheirolepis Agassiz. Transactions of the Royal Society of Edinburgh 62:53-83.

Piveteau, J. 1935. Paléontologie de Madagascar. XXI. Les Poissons du Trias inférieur. Contribution à l'étude des actinoptérygiens. Annales de Paléontologie 23:81-180.

Rayner, D. 1948. The structure of certain Jurassic holostean fishes with special reference to their neurocrania. Philosophical Transactions of the Royal Society of London (B) 233:287-345.

Rosen, D. E., Forey, P. L., Gardiner, B. G. and Patterson, C. 1981. Lungfish, tetrapods, paleontology, and ple- 
siomorphy. Bulletin of the American Museum of Natural History 167:159-276.

Saint-Seine, P., de 1949. Les Poissons de calcaires lithographiques de Cérin (Ain). Nouvelles Archives du Muséum d'Histoire Naturelle de Lyon 2:1-357.

Schaeffer, B. 1960. The Cretaceous holostean fish Macrepistius. American Museum Novitates no. 2011:1-18.

1967. Late Triassic fishes from the western United States. Bulletin of the American Museum of Natural History 135:287-342.

- 1971. The braincase of the holostean fish Macrepistius, with comments of neurocranial ossification in the Actinopterygii. American Museum Novitates no. 2459:1-34.
1978. Redfieldiid fishes from the Triassic-Liassic Newark Supergroup of eastern North America. Bulletin of the American Museum of Natural History 159:129174.

Stensiö, E. A. 1932. Triassic fishes from East Greenland collected by the Danish expedition in 1929-1932. Meddelelser om Gronland 83(3): 1-305.

Wenz, S. 1968. Complements à l'étude des Poissons actinoptérygiens du Jurassique francaise. Centre National de la Recherche Scientifique, Paris, 276 pp.

Wiley, E. O. 1976. The phylogeny and biogeography of fossil and Recent gars (Actinopterygii, Lepisosteidae). University of Kansas Museum of Natural History, Miscellaneous Publications 64:1-111. 